\title{
Human Capital Investment and the Gender Division of Labor in a Brawn-Based Economy
}

\author{
Mark M. Pitt, \\ Brown University \\ Mark R. Rosenzweig, and \\ Yale University \\ Nazmul Hassan \\ Dhaka University (Bangladesh)
}

\begin{abstract}
We use a model of human capital investment and activity choice to explain facts describing gender differentials in the levels and returns to human capital investments. These include the higher return to and level of schooling, the small effect of healthiness on wages, and the large effect of healthiness on schooling for females relative to males. The model incorporates gender differences in the level and responsiveness of brawn to nutrition in a Roy-economy setting in which activities reward skill and brawn differentially. Empirical evidence from rural Bangladesh provides support for the model and the importance of the distribution of brawn.
\end{abstract}

\section{Keywords}

Brawn; health; schooling; gender

\begin{abstract}
Emerging evidence suggests that returns to investments in schooling and health systematically differ across men and women across a variety of settings. In particular, investments in health augment the schooling of women relative to men but increase the earnings of men relative to women, while investments in schooling have greater returns in the labor market for women. Two recent prominent randomized field experiments (Miguel and Kremer, 2004; Maluccio et al., 2009) in which the health of young children was experimentally increased, for example, indicated that schooling outcomes were improved significantly for females, but not in all cases for males. In Miguel and Kremer, although school attendance rates increased for both males and females in the first year of their deworming experiment in Kenya, only the school participation rates of girls in the second year of the experiment were statistically significantly higher in either treatment school compared with the control schools, and the point estimates were from $56 \%$ to $139 \%$ higher
\end{abstract}

Notes: Center Discussion Papers are preliminary materials circulated to stimulate discussions and critical comments.

This paper can be downloaded without charge from the Social Science Research Network electronic library at: http://ssrn.com/ abstract $=1673314$

An index to papers in the Economic Growth Center Discussion Paper Series is located at: http://www.econ.yale.edu/ egcenter/ publications.html 
in magnitude for the girls (Table VIII, Panel B). And in Maluccio et al., the schooling attainment of girls but not boys was significantly increased as the result of a nutritional supplement provided in the first three years of life to children in Guatemala.

Recent reviews of the returns to schooling also suggest that the returns to human capital investment are higher for women. Dougherty (2005), reviewing 27 studies reporting estimates of rates of return to schooling based on US data, found that in 18 the schooling coefficient was higher for females, while in only one study was the estimated return higher for males. Trostel et al. (2002) obtained estimates of schooling for 28 mainly developed counties and found that in only four countries was the schooling coefficient higher for men. And of the estimated gender-specific returns to schooling reported for 95 countries by Psacharopoulos and Patrinos (2004), 72 are higher for women.

The higher female return to schooling cannot simply be attributable to the scarcity of female schooling. Another emerging fact is that in many counties of the world, schooling levels and attendance rates of females exceed those of males. This phenomenon is not confined to developed countries. In Bangladesh, for example, secondary school enrollment rates for girls even in rural areas is now higher than that of boys and in China enrollment rates of girls in secondary and tertiary schools has been higher than that of boys since 2005. There is less systematic empirical evidence on the direct labor market returns to increased health by gender. Thomas and Strauss (1997), in one of the first empirical studies to account for the endogeneity of health in estimating the earnings effects of health, find that in urban Brazil, while men with greater body mass earn higher wages, the average relationship between this measure of nutritional status and wages for women was essentially zero. ${ }^{1}$ Consistent with this result, Martorell et al.(2009) found that the nutritional supplement provided to children in the first three years of life in the randomized field experiment in Guatemala increased the wage rates of men, but not those of women.

In this paper we construct and empirically apply a parsimonious model of investment in human capital incorporating heterogeneity in brawn that seeks to account for all of these facts describing gender differentials in the levels and returns to human capital investments in any economy in which brawn is productive. We test the model using new panel data from rural Bangladesh covering a twenty-five year period when both schooling and health improved substantially in the population. Our framework departs from standard models of human capital investment in two ways. First, we embed the model in an economy described by the Roy (1951) model. Workers are bundles of two attributes - brawn and skill - and the returns to each of these attributes differs across activities. Individuals endowed with different levels of brawn optimally invest in schooling and nutritional intake and also optimally select an occupation that maximizes a welfare function. Almost all empirical work on the returns to schooling adopt a framework that assumes attributes of workers are priced identically across activities, and thus cannot account for gender differences in attribute returns or explain occupation selection. The Roy model is a natural framework with which to examine gender differentials, particularly given the marked differences in occupational

\footnotetext{
${ }^{1}$ In their study they also found that returns to schooling among wage workers was higher for women than for men.
} 
distributions of men and women. Our model can account for both the differentials in attribute returns and the gender division in occupations.

Our second departure from standard models of human capital investment is that we embed in the model two biological facts about brawn. The first is that men are substantially stronger than women on average; men have a comparative advantage in brawn (Günther $e t$ al., 2008). The top panel of Figure 1 displays the distribution of measures of grip strength obtained from a sample of US men and women (Mathiowetz et al., 1985). The bottom panel of the Figure plots the grip strength of men and women in rural Bangladesh from our data, described below. Two features are evident: first, in both populations men are substantially stronger than women -indeed, in the rural Bangladesh sample, $40 \%$ of men are stronger than the strongest women, and second, the distributions by gender across the populations are similar, consistent with these differences having biological rather than cultural or economic origins. The second biological fact we embed in the model, which is less well-known, is that increases in body mass increase strength substantially more for men than for women. This gender difference in the biological relationship between body mass and brawn has been documented in the medical literature (e.g., Round et al., 1999)). ${ }^{2}$ As part of our empirical analysis we show that this significant gender difference in the returns to nutrition is also true in our sample.

Prior empirical applications of the Roy model have not been used to address gender differentials in schooling returns or returns to brawn. Morever, starting with the pioneering work of Heckman and Sedlacek (1987), empirical applications of the Roy model have assumed that worker attributes are exogenous and that there are only two activities. In our model, both worker attributes and occupation are optimally chosen and workers can select among an infinity of activities, as in the recent Roy-type model of Ohnsorge and Trefler (2007). Only recently have studies empirically examined the role of brawn in labor markets, but these studies implicitly or explicitly adopt a framework in which returns to attributes are equalized across activities. Behrman et al. (2009) estimate an earnings function that is linear in skill and brawn. Our estimates reject the linear specification, which replicates the Behrman et al. finding of no linear brawn effects, but find that, consistent with our framework, brawn returns vary significantly with the brawn-intensity of activities. ${ }^{3}$ Rendall (2010) calibrates a model of the US economy incorporating gender differences in comparative advantage by brawn and skill that seeks to explain the aggregate changes in the wages and employment of women as arising in part from technical change that is biased against brawn. In that model, however, the returns to skill and brawn are assumed to be equalized across activities, so the model cannot be used to explain gender differentials in returns to schooling that are evident in the US economy, and relationships between schooling investment and brawn are assumed rather than estimated.

\footnotetext{
${ }^{2}$ The difference is believed to be a function of differences in levels of testosterone.

${ }^{3}$ Thomas and Strauss obtain results consistent with differential attribute returns by activity. They find that returns to health are inversely related to the average educational level of occupations. More interestingly, they find that among women, body mass and the wage is only positively associated in low-education occupations, with health and wages unrelated on average. Their study, however, does not attempt to take into account optimal occupational selection.
} 
We use data from rural Bangladesh because of the existing rich information at the individual level on anthropometrics and consumption. Rural Bangladesh, however, is clearly a brawnbased economy. The occupational distribution, by gender, for urban and rural adult populations in 2004 in Bangladesh is typical of that for low-income rural areas. Table 1, from the 2004 Demographic and Health Survey for Bangladesh, shows that roughly twothirds of the men in rural areas are engaged in activities - e.g., farming, rickshaw pulling and other manual labor -in which brawn is presumably productive. On the other hand, less than $25 \%$ of women are in the labor force; there is clearly a division of labor by gender.

Although it is attractive to think of economic development as raising the returns to skill relative to brawn, the rise in and overtaking of the schooling of girls relative to boys in rural areas of Bangladesh was not the result of changes in technology. The solid line in Figure 2 shows the ratio of girl to boy secondary school enrollment rates over the period 1981-2002 from published government sources (Bangladesh Bureau of Educational Information and Statistics, 1987, 1991, 1998, 2003). As can be seen, relative schooling growth for girls has been substantial. The top discontinuous line, which plots the movement in agricultural wages over the same period, shows, however, that there has been little or no growth in real wages over this time interval. Agricultural wages are closely related to agricultural productivity (Rahman, 2009), so the differential trends in schooling are evidently not the result of productivity growth or technical change. The rising relative schooling trend also cannot be explained by the growth in micro credit. The fraction of adult rural women who are micro credit clients is plotted at the bottom of the figure; as can be seen, the schooling trends began long before microcredit became an important source of loans for rural women. Bangladesh has put in place a number of educational initiatives that subsidize schooling, including subsidies that favor female relative to male schooling. While studies have shown that these initiatives have been successful in increasing schooling and the relative schooling of girls (Ravallion and Wodon, 2000; Khandker et al., 2003), these programs may have accelerated but could not have initiated the relative rise in female schooling seen in the figure, as the relative trends in schooling began before any of these programs were in place.

A major initiative underway in the early 1980's in Bangladesh was the reduction in diarrheal disease and child mortality in part through educational campaigns that provided information on the importance of clean water and through improvements in water sources. The middle discontinuous line in Figure 2 plots the increase in the fraction of the rural population with improved water sources. This line indeed parallels the trend in the relative gender-specific school enrollments and, as documented below, the height and body mass of both men and women rose over the period without any increase in the per-capita caloric intake (Hels et al., 2003), consistent with a decline in morbidity, which increases the efficacy of nutritional intakes. It is not possible, of course, to infer causal effects from increased body mass to gender-specific changes in schooling from these aggregate associations. Health interventions and improved nutrition also contributed to declining maternal mortality (Hogan et al., 2010)), which may have also affected the relative return to female schooling (Jayachandran and Lleras-Muney, 2009). Our objective is not to decompose the trends in relative schooling investments by cause in Bangladesh, but rather to estimate how changes or variation in brawn affect schooling and activity choice and the returns to schooling by gender in a 
framework that is consistent with these temporal changes and the observed differences by gender in schooling levels, returns and activities in most economies.

In section 1 of the paper we set out the model of human capital investment incorporating the production of brawn and skill within a Roy economy. The model delivers implications for how variation in body mass endowments and changes in the efficacy of nutritional intake affect schooling and activity choices differentially by gender when health and schooling are complements. Among the key implications of the model are that comparative advantage in brawn affects activity choice and thus the relative returns to the two attributes and that increases in body mass increase the schooling of females relative to males. The next section describes the data that are used in the empirical analysis and presents descriptive statistics on changes in nutrition, anthropometrics and schooling between 1981-2 and 2001-2. In section 3 the method for measuring body mass endowments using information on body mass and individual-specific nutrient intakes, which replicates the methods and findings in Pitt et al. (1990), is set out and the strategy for estimating the effects of the estimated endowments in the presence of measurement error is described.

In sections 4-6 of the paper reduced-form estimates of the relationships between the individual body mass endowments and direct assessments of strength, the probabilities of attending school, completed schooling attainment and participation in energy-intensive occupations are obtained separately for men and women. The results confirm that body mass translates into brawn for men substantially more than for women and indicate that, consistent with the model, males with larger body mass endowments are less likely to attend school when young, have lower completed schooling and are more likely to be engaged in energy-intensive activities as adults compared with males with a smaller endowed body size. In contrast, larger women are marginally more likely to be in school and have higher levels of schooling and participate less in less energy-intensive activities compared with smaller women, consistent with health-schooling complementarity. In section 7 we consider two alternative explanations for our findings on the contrasting gender-specific effects of body mass on schooling and activity choice: that larger men are no more productive but are simply less inherently skilled and that larger women have a higher age at menarche, which extends their marriage age and schooling. Our estimates do not support these alternatives. We find that while body mass is positively associated with wages for men it is not significantly correlated with performance on the Ravens Matrices test for either men or women, and that age at menarche for larger women is lower not higher, in accord with medical evidence.

The penultimate section of the paper is devoted to estimating a wage function that is consistent with the Roy model in which schooling and activities are optimally selected and in which activities reward brawn and schooling differentially. The results indicate that the log-linear wage function that assumes equality of returns across activities commonly estimated in the literature is rejected, indicating that schooling has a higher return and brawn a lower return in low energy-intensive occupations. Given that women are less-represented in energy-intensive activities, on average the return to schooling is higher among women than among men. The final section contains a brief summary and considers the implications 
of our findings for the effects of alternative development polices on gender gaps in earnings and schooling and the gender division of labor.

\section{The Roy Economy, Human Capital Production and Activity Choice}

We assume that investments in schooling and health (body mass) and the choice of activities (occupation) are made in a Roy-type economy. Specifically, there is a continuum of tasks or industries indexed by $i$ and each worker provides a bundle of skill $H$ and brawn $B$ to carry out the tasks. ${ }^{4}$ Firms in the economy produce outputs that are the sum of the individual outputs of workers from each task. The marginal contribution of a worker to the total output of the firm is thus the worker's task output. Assuming a Cobb-Douglas technology for the task function, the adult worker wage, the value of a worker's contribution to task output, is given by:

$$
W=\pi(i) v(i)(\kappa H)^{\alpha(\mathrm{i})} B^{(1-\alpha(\mathrm{i}))} \quad(1)
$$

where $\pi(i)=$ the equilibrium price of the output of task $i, v(i)=$ a task-specific productivity parameter, and $\kappa=$ is a scale parameter that converts $H$ into units of brawn,

Following Ohnsorge and Trefler (2007), we order without any loss of generality occupations/tasks by skill intensity so that $\alpha_{i}>0$, where $\alpha_{i}=\partial \alpha / \partial i$; thus a higher $i$ means a more-skill-intensive task by definition. That is,

$$
\text { if } i^{\prime}>i \text {, then } \alpha\left(i^{\prime}\right)>\alpha(i) \text {. }
$$

Brawn is a function of body mass $M$; the production technology for brawn is given by

$$
B=B(\gamma M)+b,
$$

where $\gamma \geq 0, B_{M}>0, \mathrm{~B}_{M M}<0 . \gamma$ is a parameter that will be used to capture differences in the relationship between body mass and brawn by gender. We assume that increased body mass increases brawn for males, and not (or much less so) for females, consistent with the biomedical literature. ${ }^{5}$ The brawn of females is thus given by the endowment $b$. Each individual is also endowed with an individual-specific body mass $m$. Body mass can be augmented by effective calorie intake $\theta C$, that is nutrients that are retained by the body, where $C=$ calorie intake and $\theta$ reflects the proportion of calories retained or the efficiency by which calories increase body mass. We assume that decreases in morbidity, brought about by public health interventions, increase $\theta$. The body mass production function is:

$$
M=M(\theta C)+m, \quad(3
$$

\footnotetext{
${ }_{5}^{4}$ In the Roy-model variant set out by Heckman and Sedlacek (1985), there are two sectors, but a vector $n$ of worker attributes. ${ }^{5}$ We will directly test this assumption with our data.
} 
where $\theta>0, M_{1}>0, M_{11}<0$.

The skill production function is

$$
H=H(S ; M),
$$

where $S=$ schooling time and $H_{1}>0, H_{2}=0$. We assume that a higher body mass (or, equivalently, increased nutrition) increases the return to schooling $S$ in augmenting skill, so that $H_{12}>0$. That is, schooling and health are complements in the production of skill, but health does not directly augment skill. Finally the wage of a child $\omega$ is an increasing function of brawn, but not schooling:

$$
\omega=\omega(B)
$$

where $\omega_{B}>0, \omega_{B B}<0$

To fix ideas using the simplest optimizing model, we assume that a parent chooses schooling time, calorie consumption and the adult activity of a child to maximize a utility function that has as arguments the adult wage of the child and his or her effective calorie consumption. The optimization program is:

$$
\max _{C, S, i} \mathrm{U}(\theta C, W)
$$

subject to the technologies (1)-(5) and to the budget constraint

$$
F=p C+(1-S) \omega+S \rho,
$$

where $F=$ parental income, $p=$ the market price of a calorie and $\rho=$ the direct cost of a unit of schooling time. The budget constraint reflects the fact that children work and contribute to income when not in school. ${ }^{6}$

We first solve the model for the case in which $\gamma=0$, so that increases in body mass do not augment brawn. This variant of the model thus more closely describes optimal schooling and activity choices for women. For $\gamma=0$, the FONC are:

$$
\begin{gathered}
\theta \mathrm{U}_{C}=\lambda p \\
U w \alpha(i) H_{1} W / H=\lambda[\omega+\rho]
\end{gathered}
$$

${ }^{6}$ In the empirical application, we allow children to participate in three activities: schooling, work and home time. Adding a third activity for children would not alter the main results from the model. 


$$
\log (\kappa H / B)=-\left(\pi_{i}+v_{i}\right) / \alpha_{i} \pi(i)
$$

Expressions (8) and (9) are standard, indicating that the marginal cost of a calorie is its market price and schooling has a direct and opportunity cost. The third first-order condition, however, reflects the optimal activity choice in the Roy economy. Expression (10) has two important implications: (a) activity choice depends only on a worker's relative amounts of brawn and skill, not on the absolute amounts - comparative advantage - and (b) in an economy in which the ratio of skill to brawn is less than one (a brawn-based economy), the task price or task productivity must rise as skill-intensity rises $\left(\pi_{i}>0\right.$ or $v_{i}>0$, where $\pi_{i}=\mathrm{d} \pi / \mathrm{d} i$ and $\left.v_{i}=\mathrm{d} v / \mathrm{d} i\right)$. This is because for a worker for whom $\log (\kappa H / B)<0$, a shift to a higher $\alpha(i)$ activity would lower his or her output and thus wage, so either the task price or task productivity must be higher to compensate him or her for moving. ${ }^{7}$

For men, $\gamma>0$, the FONC for schooling and activity choice are the same as for women, but that for calories is different:

$$
\theta\left(\mathrm{U}_{C}+\gamma B_{M}(1-\alpha(i)) \mathrm{U}_{W} W / H\right)=\lambda\left[p-\gamma S \omega_{B} \theta M_{1} B_{M}\right]
$$

Comparing (8) and (11), we see that the returns to calorie consumption are higher for males and the net price of calories is lower, as calories augment income provided by boys. ${ }^{8}$ Thus, males receive more calories than females for two reasons: (a) Calories increase the wage more for men and (b) men work in more calorie(brawn)-intensive activities with a higher return to brawn than do women, as the ratio $H / B$ is lower for men. But (9) also indicates that if men are in more brawn-intensive activities because of their higher endowed brawn, the returns to investments in schooling are also lower for men on average.

We now use the model to ascertain (a) how investments in public health that reduce morbidity and thus increase calorie efficacy affect optimal human capital investments and activity choices for men and women; that is, how $S, C$, and $i$ change, by gender, when $\theta$ increases and (b) what happens to $S$ and $i$ when $m$ increases among males. The latter implications will be directly estimated, but we show that the relationships between $m, S$, and $i$ are informative about the changes resulting from interventions that affect $\theta$.

We derive from the model, the following proposition:

\section{Proposition 1}

When brawn is not affected by calorie consumption $(\gamma=0)$ a reduction in morbidity must increase schooling, decrease calorie consumption and increase the average skill-intensity of occupations as long as effective calories do not decrease.

\footnotetext{
${ }^{7}$ This property of the model is also true when the task function is CES. We have not modeled the general-equilibrium properties of the economy. The condition that task value $(\pi(i) v(i))$ rises as the relative returns to skill increase could be due to more skill-intensive activities having higher levels of capital or due to brawn-intensive tasks producing non-tradeable output so that output prices for such tasks are lower where brawn is in plentiful supply. We test this property below.

${ }^{8}$ This point was originally made by Gersovitz (1983) for subsistence economies.
} 
Proof-Assume that $\mathrm{U}_{C}+\theta C \mathrm{U}_{C C} \leq 0$, then

$$
\begin{gathered}
\mathrm{d} S / \mathrm{d} \theta=-\left(\alpha(i) C H_{12} \mathrm{U}_{w} W / H\right) \Phi_{22}+\left(\mathrm{U}_{C}+\theta C \mathrm{U}_{C C}\right) \Phi_{21}>0 \\
\mathrm{~d} C / \mathrm{d} \theta=\left(\alpha(i) C H_{12} \mathrm{U}_{w} W / H\right) \Phi_{21}-\left(\mathrm{U}_{C}+\theta C \mathrm{U}_{C C}\right) \Phi_{11}<0 \\
\mathrm{~d} i / \mathrm{d} \theta=\left(\alpha(i) C H_{12} \mathrm{U}_{w} W / H\right) \Phi_{32}-\left(\mathrm{U}_{C}+\theta C \mathrm{U}_{C C}\right) \Phi_{31}>0
\end{gathered}
$$

where

$$
\begin{aligned}
& \Phi_{22}=-p^{2}\left(\pi_{i i} / a(i) \pi(i)-\pi_{i} /\left(a_{i i}\right)^{2} \pi(i)-1 / a_{i} \pi_{i}\right) / \Delta<0 \\
& \Phi_{21}=-p(\omega+\rho)\left(\pi_{i i} / a(i) \pi(i)-\pi_{i} /\left(a_{i i}\right)^{2} \pi(i)-1 / a_{i} \pi_{i}\right) / \Delta<0 \\
& \Phi_{11}=-(\omega+\rho)^{2}\left(\pi_{i i} / a(i) \pi(i)-\pi_{i} /\left(a_{i i}\right)^{2} \pi(i)-1 / a_{i} \pi_{i}\right) / \Delta<0 \\
& \Phi_{32}=-p^{2}\left(H_{1} / H\right) / \Delta>0 \\
& \Phi_{31}=-p(\omega+\rho)\left(H_{1} / H\right) / \Delta>0 \text { by second-order conditions }
\end{aligned}
$$

This proposition says that the reduced-form relationship between an intervention reducing morbidity and schooling, as in the randomized interventions of Miguel and Kremer (2004) and Martorell et al. (2008), will reflect the complementarity in skill production, for girls. However, from (12), even if schooling and health are not complements in the production of skill $\left(H_{12}=0\right)$, schooling may increase when morbidity is reduced because health and the wage are substitutes in the utility function. This is just the basic point that reduced-form interventions usually cannot identify technology. More importantly,

\section{Proposition 2}

When brawn is increased by calorie consumption $(\gamma>0)$, as for men, a reduction in morbidity may increase or decrease schooling and the average skill-intensity of occupations as long as effective calories do not change significantly.

Proof of proposition 2-Assume that effective calories do not change, so that $\mathrm{U}_{C}+$ $\theta C \mathrm{U}_{C C}=0$, then:

$$
\begin{aligned}
& \mathrm{d} S / \mathrm{d} \theta=-\left(\alpha(i) C H_{12} \mathrm{U}_{w} W / H+\gamma C H_{1} W^{2} \mathrm{U}_{W W}(1-\alpha(i)) \alpha(i) / H B-\lambda \gamma \omega_{B} B_{1}\right) \Phi_{22}-\left(\gamma C B_{1} M_{1} / B\right) \Phi_{32} \\
& \mathrm{~d} i / \mathrm{d} \theta=-\left[\alpha(i) C H_{12} \mathrm{U}_{w} W / H+\gamma C H_{1} W^{2} \mathrm{U}_{W W}(1-\alpha(i)) \alpha(i) / H B-\lambda \gamma \omega_{B} B_{1}\right] \Phi_{32}+\left(\gamma C B_{1} M_{1} / B\right) \Phi_{33}
\end{aligned}
$$

Where

$$
\begin{aligned}
& \Phi_{22}=-\left[p-\gamma S \omega_{\mathrm{B}} \theta M_{1} B_{M}\right]^{2}\left(\pi_{i i} / a(i) \pi(i)-\pi_{i} /\left(a_{i i}\right)^{2} \pi(i)-1 / a_{i} \pi_{i}\right) / \Delta<0 \\
& \Phi_{32}=\left[p-\gamma S \omega_{B} \theta M_{1} B_{M}\right]\left[\gamma B_{M} a_{i} U_{W} M_{1} \theta W(\omega+\rho) / B+a_{i} U_{W} H_{1} W\left(p-\gamma S \omega_{B} \theta M_{1} B_{M}\right) / H\right] / \Delta<0 \\
& \Phi_{33}<0, \text { by second-order conditions }
\end{aligned}
$$


Comparing (12) to (15), the effects of changes in $\theta$ on $S$, we see that for men there are additional negative terms reflecting the fact that increasing body mass for men both raises the opportunity cost of schooling and lowers the return to schooling, as it alters men's comparative advantage in favor of participating in more brawn-intensive activities. The net effect on schooling of an intervention reducing morbidity for males thus may be negligible or even negative, even if schooling and health are complements, as is assumed.

The model also indicates that among males larger men may receive less schooling and be over-represented in brawn-intensive activities:

\section{Proposition 3}

If brawn and body mass are positively related, an increase in body mass may increase or decrease schooling and the average skill-intensity of occupations.

\section{Proof of proposition 3}

$$
\begin{aligned}
& \mathrm{d} S / \mathrm{d} m=\left(-\gamma B_{1} \alpha(i) H_{1}\left[(1-\alpha(i)) W / H B+\mathrm{U}_{W W} W / H\right]+\lambda \gamma \omega_{B} B_{1}\right) \Phi_{22}-\left(\gamma B_{1} / B\right) \Phi_{32} \\
& \mathrm{~d} i / \mathrm{d} m=\left(-\gamma B_{1} \alpha(i) H_{1}\left[(1-\alpha(i)) W / H B+\mathrm{U}_{W W} W / H\right]+\lambda \gamma \omega_{B} B_{1}\right) \Phi_{32}+\left(\gamma B_{1} / B\right) \Phi_{33}
\end{aligned}
$$

Because larger men have more brawn, they will have higher opportunity costs of schooling and will participate in activities with lower returns to schooling. This will lower the returns to schooling; on the other hand; offsetting this is that health (body mass) and the adult wage are substitutes in the utility function and complements in the production of skill $\left(H_{12}>0\right)$.

Proposition (3) has unambiguous implications for differences in the effects of augmenting nutrition for men and women and for differences in observed schooling levels and returns:

\section{Lemma 1}

If brawn and body mass are positively related only for males, then increases in body mass for everyone will decrease schooling for males relative to females and increase the gender division of labor (difference in average $a(i)$ ).

Increasing body mass for men, but not women, raises the opportunity cost of schooling and directly lowers the relative return to schooling through occupation selection. This offsets any positive effects of reductions in morbidity on schooling investment only for males.

\section{Lemma 2}

If men have more brawn than women, both the amounts of schooling of women and the "returns" to schooling may be higher for women than for men, since men will be in lower- $a$ occupations.

Finally, the model also gives rise to the following lemma: 


\section{Lemma 3}

The estimated returns to schooling for men $=\mathrm{a}(i) \mathrm{d} \log H / \mathrm{d} S$ may be biased (upward) downward relative to women if brawn heterogeneity is not taken into account in estimating wage functions and brawnier men obtain (more) less schooling.

Proof-Substitute (2), (3) and (4) into the wage equation (1), then

$$
\mathrm{d} \log W / \mathrm{d} S=\alpha(i) \mathrm{d} \log H / \mathrm{d} S+(1-\alpha(i))(\operatorname{dlog} B / \mathrm{d} m) \mathrm{d} m / \mathrm{d} S
$$

The first term in (19) is the effect of schooling on the log wage due to schooling increasing skill, the "return" to schooling. The second term arises from optimal schooling choice. From (2), (3) and (17), $\operatorname{d} \log B / \mathrm{d} m>0$ but $\mathrm{d} m / \mathrm{d} S$ may be positive or negative for men; it is possible that this additional "bias" term may be negative. For women, $\mathrm{d} m / \mathrm{d} S=0$ so there is no brawn heterogeneity bias for women. Thus there are two potential reasons that the observed relationship between schooling and wages on average is higher for women than for men: (a) men, based on their comparative advantage, will be concentrated in brawn-intensive, low$a(i)$ occupations compared with women and (b) the estimated average relationship between wages and schooling for men may be biased downward if brawn is not taken into account and if brawnier (larger) men obtain less schooling.

\section{The Data}

The principal objectives of our empirical analysis are to estimate gender-specific effects of individual body-mass endowments on schooling and occupation choice to test the model of school investment and activity choice incorporating brawn production and to estimate a wage function that is consistent with the Roy assumption that schooling and brawn differentially affect wages across occupations. To carry out the analysis, described below, requires at a minimum data that provides individual-specific nutrient intakes, anthropometric measures, schooling, wages and activity choices. We use three data sets describing households in rural Bangladesh that meet these criteria. The first data set is the Nutrition Survey of Rural Bangladesh 1981-2 (N=4,107), a probability sample of 50 households in each of 15 villages meant to be representative of the rural population of Bangladesh in the year the survey was administered. These data were used by Pitt et al. (1990) to estimate body mass endowments and to assess how these affected the allocation of nutrients among children and adults within households.

The second data set we use is from the Nutrition Survey of Rural Bangladesh 2001-2 (N= 9,838). This survey was a follow-up to the 1981-2 survey and includes all surviving and resident individuals surveyed in 1981-2 in fourteen of the fifteen original villages plus a new random sample of households in the same villages. All individuals in the original survey and all members of their households were included in the panel no matter where their residence in 2001-2. Attrition of surviving individuals who still resided in Bangladesh at the time of the survey was less than 3\%. The third data set is from the Nutrition Survey of Rural Bangladesh 2007-8 ( $\mathrm{N}=12,244)$, which includes all individuals surveyed in 2001-2 and all members of their households, again regardless of residence at the time of the survey. 
These data sets have a number of important and unique features that facilitate the analysis. First, as noted, there are individual-specific food intakes, recorded over a 24-hour period by observation and measurement, for all individuals in each round, except for the first survey in which this information was obtained for only a random $50 \%$ of households. Second, individual-specific activity schedules were obtained for the same 24-hour period, in addition to occupation information. Third, individual anthropometric information on height and weight was obtained from all individuals in all rounds. These data together enable the estimation of the body mass production function and thus body-mass endowments, as described below. In addition, households in two of the villages were interviewed multiple times in the same year in each survey round. This validation subsample included four repetitions in 1981-2 and two repetitions in 2001-2 and in 2007-8. The repetition subsamples will enable us to correct for measurement error in our estimates of the effects of body mass endowments on human capital choices and wages. Fourth, in the 2007-8 round of the survey we obtained individual-specific assessments of grip strength, pinch strength and aptitude (Raven's matrices) for every respondent meeting a minimum age requirement. Data from these instruments will enable us to directly assess whether body mass differentially affects brawn by gender and to identify any correlation between body mass and cognitive ability that may bias our estimates. Finally, the combination of long-term panel information and repeated random cross-sections will enable us both to assess the robustness of our structural (production function) estimates to environmental changes over a twenty-year period as well as to assess the effects of body mass endowments on both contemporaneous schooling investments and subsequent completed schooling and adult wages.

The activity information in the 1981-2 and 2001-2 surveys is consistent with the official statistics on rural school enrollment trends. As seen in Figure 3, which plots the fraction of children aged 10-15 attending school by age and gender, there has been a substantial rise in school attendance at every age for both boys and girls but the increase has been greater for girls such that in the 2001-2 round of the survey girls' school attendance is greater than that of boys for all ages above age 6, a reversal of the differences in 1981-2. During this period both boys and girls in this age range also experienced increases in body mass. Figure 4 depicts the changes in the body mass index (BMI) for girls and boys across the survey interval. Boys appeared to have experienced a somewhat greater increase in BMI than girls: for boys, BMI has increased at every age between 5 and 15; the BMI for girls is higher in the later period only for girls above 9. And, above that age the percentage increase in BMI for boys is $7.1 \%$ while that for girls is $2.2 \%$. The data also indicate that stature has increased in the rural population. The top panel in Figure 5 plots the heights of respondents in the 1981-2 and 2001-2 survey rounds by the age at which the respondent reached 22. These show steady increases across cohorts for both men and women.

The gains in height and body mass have not been due to increased nutrient intakes. The bottom panel of Figure 5 shows that the level and allocation of calories per person, based on the individual-specific calorie information taken from comparable months across the survey years, has not significantly changed over the period: average caloric intake is higher for men and for women in both periods, consistent with our model in which the brawn effects of nutrition differ by gender, but average calories levels within gender groups, have not increased for either group. It is thus likely that the gains in stature and body mass were due 
to the reductions in morbidity, which increased the efficacy of nutrient intakes as there has not been a decrease in activity levels, at least for men. The data indicate that in 1981-2 67\% men aged 20-49 were engaged in "exceptionally active" or "active" occupations, based on energy expenditure levels; in 2001-2 the proportion increased to $72 \%$. For women, only $9 \%$ were participating in such activities, and that proportion declined to $3 \%$ in 2001-2. These figures thus suggest that, consistent with the predictions of the model, over the twenty-year period in which there were significant increases in the health of the population, the comparative advantage of women in skill increased as did the division of labor by gender.

\section{Estimation Strategy: Identifying Body Mass Endowment Effects}

To assess the effects of changes in body mass for males and females on schooling choice and occupation selection and to estimate wage functions incorporating schooling and body mass in which the returns to skill and brawn vary across occupations consistent with the Roy model we carry out our estimation strategy in three steps. We describe the first two steps here, deferring the discussion and estimation of the activity-specific Roy-model wage function to the final section.

The first step in our empirical analysis is to obtain estimates of body mass endowments for the sampled respondents. To do this, we estimate the body-mass production function (3) using the same specification and econometric methodology as in Pitt et al. (1990) but applied to the 2001-2 round of data, which contains many more individuals. As in that study, we generalize (3) to allow activity type to directly affect body mass, because activity type affects energy expenditure. In the earlier study weight/height was used as the body mass measure to obtain an estimate of the body-mass endowment because it is especially sensitive to contemporaneous variations in nutrient intakes and activities (energy expenditure). Because measures of inputs and anthropometric outcomes were obtained in the same interview period, the contributions to the short-run variation in body mass from endogenous variation in inputs $(C)$ can be identified.

The empirical challenge to obtaining an estimate of the body mass endowment from the production function is that, as shown in the model, the nutrient inputs and the activity-type will be correlated with the unobserved endowment that is impounded in the error term. We replicate the methodology in Pitt et al. and employ instrumental variables, using as instruments village-level prices interacted with an individual's age, his or her household land holdings and the household head's characteristics - age and schooling. Because we are using the same specification and estimation procedure as in the earlier study, we expect that the estimated coefficients corresponding to the work activities, nutrients, age, and gender variables obtained from the 2001-2 population will be the same as those obtained from the 1981-2 data, despite the small overlap in the population, if the specification and estimation procedure identify structural, biological effects. ${ }^{9}$ We will directly test the robustness of the estimates to the changes in environmental conditions that occurred over the twenty-year interval between surveys. Among the conditions that importantly changed during the time

${ }^{9}$ Less than $16 \%$ of the sample respondents in 2001-2 were among the 1981-2 respondents for which there was individual-specific food intake information necessary for estimating endowments. 
period, aside from the relative prices of foods and nonfoods and schooling, are the sources of water used (increased availability of wells) and water use habits. The specification will also include controls for water sources. Because over the period information was diffused about water purification and about the relative purity of the different sources of water, we expect that the coefficients on the water-source variables will, in contrast to those for nutrients and activities, have shifted over time. That is, a well in 1981 is not the same as a well in 2001.

The residuals from the estimated body-mass production function contain the body mass endowments for each sample respondent $j$. We will use these to estimate the reduced-form endowment effects on schooling (attainment and attendance), activity choice and the (male) wage that correspond to the comparative statics of the model. That is, we estimate

$$
y_{j}=Z_{j} \zeta+b m_{j}+\varepsilon_{j}, \quad(22)
$$

where $y_{j}=S_{j}, W_{j}, i_{j} ; m_{j}=$ the production function residual; the $\boldsymbol{Z}_{\mathrm{j}}=$ a vector of exogenous control variables; and $\varepsilon_{j}=$ an error term, containing measurement error in the $y_{j}$. The main empirical problem is that the residual $m_{j}$ for individual $j$ contains the individual's true body mass $m_{j}{ }^{*}$, net of the influence of contemporaneous consumption and activities, plus measurement error $\eta_{j}$; i.e., $m_{\mathrm{j}}=m_{j}{ }^{*}+\eta_{j}$, where $m_{j}{ }^{*}=$ the true endowment. Estimation of (22) by OLS would thus yield biased estimates of both the coefficient vector $\zeta$ and $b$.

To deal with the measurement error problem, we use repeated measures from the validation samples of within-round replicates - households that were visited multiple times within the same year. For the validation subsample

$$
m_{j r}=m_{j}^{*}+\eta_{j r}
$$

where $r=$ within-year round number. If we assume classical measurement error properties for $\eta_{j}\left(\eta_{\mathrm{j}}\right.$ is uncorrelated with $\boldsymbol{Z}_{j}{ }^{*}, y_{j}{ }^{*}$, and $\left.\varepsilon_{j}\right)$ and that the repeated measures have the same mean and independent measurement errors we have a set of 'exchangeable' replicates. By jointly estimating the outcome equation (22) and the measurement equation (23) using maximum-likelihood we can obtain consistent estimates of the parameters in (22) as well as appropriate standard errors that take into account that the residual measures of endowments are noisy. Owing to the conditional independence between the measurement errors and the outcome $y_{j}$ given $m_{j}{ }^{*}$, the likelihood is the product of the measurement model (23) and the outcome model (22), integrated over $m_{j}{ }^{*}$, assuming normality for the errors (Rabe-Hesketh et al., 2003). We will refer to these estimates, which accommodate measurement error, as GLLAM (generalized linear latent and mixed model) estimates.

Finally, the model depicted the behavior of a pair of individuals - parent and child. In the data individuals are clustered in households with multiple members. We thus allow the allocation of resources to each individual to be a function not only of his/her own endowment but also the average endowment of other household members. We also obtain coefficient standard errors that take into account household clustering. In the empirical 
analysis we assume only that household landholdings, the household endowments, age and food prices are exogenous variables that belong in the set $\boldsymbol{Z}_{j}$.

\section{Body Mass Production Function Estimates, Body Mass Endowments and Brawn}

The first column of Table 2 reports the two-stage least squares estimates of the body-mass production function from Table 4 in Pitt et al. (1990), which were obtained using the 1981-82 survey data. The input variables include the log of individual calorie consumption over a 24-hour period, indicator variables based on the contemporaneous reported activity of the person of whether the activity was "very active" or exceptionally active" (the left out categories being "active" and "not very active"), the log of age and its square, gender and gender interacted with log age, whether the respondent was pregnant, whether the respondent was lactating, and the principal source of water for the household, divided into four categories (tube well, well, and pond, the left out variable being piped water). The prior estimates indicated that net of activities, and controlling for the state of lactation and pregnancy, increased calorie consumption increased body mass while, for given calorie intake, working in energy-intensive activities depleted body mass relative to working in less energy activities. Body mass was also reduced if the household's principal water source was not piped water. The second column of Table 2 reports the new two-stage least squares estimates of the body-mass production function from the 2001-2002 data, using the same specification and econometric method. Evidently because of the increase in sample size, the calorie and activity coefficients are measured with more precision. The point estimates, however, are not only qualitatively the same for those variable coefficients as were obtained using the earlier-round data, but are quantitatively similar, as is to be expected if structural parameters are being identified. Indeed, we cannot reject the hypothesis that the set of calorie intake, activity, age and gender variables are identical using a standard critical-level criteria. ${ }^{10}$ In contrast, the water source effects on body mass are quite different, now indicating that the household's source of water does not matter. This is consistent with households increasingly purifying water in the home so that point-source water quality is no longer a good measure of the quality of individual water intake.

We used the second-column production function estimates to compute body-mass residuals, containing the body mass endowment, for each of the sample respondents in the 2001-2 data set. We use the residual-based body mass endowment information to first estimate $\gamma$, the effect of the body mass endowment on brawn. That is, we seek to verify a major assumption of the model in our data, and confirm findings in the medical literature, that variation in body mass is related to strength more substantially for males than for females. To obtain a measure of brawn, in the 2007-8 round of the data we administered grip strength assessments to all adult sample respondents. Each respondent was asked to squeeze a dynometer three times with each hand and readings were recorded for all six applications. Our measure of brawn is the maximum of the per-hand average grip strength reading (in kilograms of pressure). For the sample of respondents aged 20-49, the mean (standard

\footnotetext{
${ }^{10}$ Specifically, this was a test of the pooling hypothesis using a likelihood ratio test.
} 
deviation) grip strength for men was 37.3 (8.36) while that for women was 24.3 (5.66). ${ }^{11}$ Men are clearly brawnier than women on average.

Table 3 reports GLS and maximum-likelihood GLLAM estimates of $\gamma$ based on the estimated body mass endowments and grip strength scores for men and women aged 20-49. The first column reports the GLS estimates for males, and indicates that men with a greater body mass endowment are significantly stronger. The GLLAM estimates making use of the auxiliary replicate subsample in column two indicate that the endowment variable, based on the residuals, is measured with error $(\rho$, the proportion of the total variance in the residual that is noise, is approximately $10 \%$ ) and the estimate of $\gamma$ corrected for measurement error, in column two, is about $10 \%$ higher than the corresponding GLS estimate that ignores measurement error. Men endowed with a larger body mass are indeed brawnier - a one standard deviation increase in the body mass endowment increases grip strength by a statistically significant $5.9 \%$. The point estimate of $\gamma$ for women, however, is less than onefourth that for men, and is not statistically significantly different from zero at the .05 significance level. The GLLAM estimates that exploit the verification sub sample indicate that the body mass endowment is measured with more error for women than for men, but the $\gamma$ estimate corrected for measurement error (fourth column) remains less than one-fourth the corresponding estimate for men. Thus, while larger women may be healthier, unlike men, they are not significantly brawnier. ${ }^{12}$

\section{Body Mass Endowments and Schooling}

We now examine the relationship between the body mass endowment and schooling investments for children aged 10-15 based on the 2001-2 round of data. We chose this age range because most children attend primary school so that almost all of the school investment variation across children is occurring above age 10 . We also we need to impose a low age ceiling, however, because of the young marriage age for girls - approximately $11 \%$ of girls in our sample aged between 15 and 25 married by age 15 . Because school attendance information is available only for household members, given that most women leave the household upon marriage, a sample of in-household girls aged over 15 would be selective. Children in this age range can be engaged in one of three principal activities - schooling, work or 'home time.' In 1981-2, of the $48.3 \%$ of boys not attending school almost $70 \%$ were working; in 2001-2, the major alternative to school for boys was also work - with over $90 \%$ of the $17.5 \%$ of boys not attending school at work. For girls, the major alternative to school is home time in both periods. $74 \%$ of the $62.4 \%$ of girls not attending school were not working in 1981-2 and $68 \%$ of the $12.5 \%$ of girls not in school were at home in 2001-2.

\footnotetext{
${ }^{11}$ Figure A in the appendix plots the distribution of test results by gender. Note that the location difference in "aptitude" is relatively trivial compared with the gender difference in strength, depicted in Figure 1. And, as discussed below, the difference in performance is almost wholly explained by the difference in schooling levels between men and women in this cohort.

${ }^{12}$ One possible alternative explanation for these results is that larger men select into occupations where they use brawn and thus develop muscle strength while women who are in relatively sedentary occupations do not. While medical evidence suggests a biological explanation for the results that is independent of activity choice, to ascertain if the gender division of labor could cause differences in the brawn-body-mass endowment relationship by gender, we estimated the endowment grip strength relationship in a subsample of males and females aged 15 and over all of whom were currently attending school at the time of the assessments, and thus whose activities did not differ. The difference in the GLLAM coefficients by gender were even stronger than those displayed in Table 3 , with the ratio of male-female endowment effects on grip strength at 7.7 to one. The estimate of $\gamma$ is statistically significant for males but not for females in this subsample as well.
} 
To accommodate the three activity alternatives, we estimate the determinants of activity choice using multinomial (ML) logit and ML logit GLLAM using the verification subsample to correct for endowment measurement error. In addition to the own endowment measure, we include the size of landholdings of the household, an indicator of whether or not the household owns any land, the average endowment of other household members, and the child's age. Because we only have endowment measures for half of the respondents in 1981-82, the sample of 10-15-year olds is too small to carry out the analysis using the firstround data. Table 4 reports the ML logit and ML logit GLLAM estimates for boys and girls in the 2001-2 sample, the left out category being school attendance. The estimated marginals and their associated t-statistics for the probability of attending school are provided in Table 5 .

Both the ML logit and the ML logit GLLAM estimates indicate that larger boys are significantly more likely to be working relative to attending school. In contrast, girls with larger body mass endowments are less likely to work. The marginals in Table 5 indicate that, consistent with the model in which increased brawn lowers the net return to schooling, boys aged 10-15 with a larger body mass endowment are significantly less likely to be attending school while larger girls in the same age group are no less likely to be in school than smaller girls. The error-corrected point estimates indicate that a boy with a body mass endowment one standard deviation higher than the mean is a statistically significant $6.6 \%$ less likely to be in school; a similar gain in body mass for girls increases the probability of being in school, but by a statistically insignificant $1.5 \%$.

To verify that body mass also affects completed schooling attainment, we make use of the 1981-2/2001-2 panel data. Based on the production function estimates from the 1981-2 data we have body mass endowments for one-half of respondents in 1981-2 as well as information on their schooling attainment and wages in 2001-2 from the second-round data. We estimate the relationship between the body mass endowments estimated for 1981-2 and completed schooling attainment (years) in 2001-2 for the sample of children aged less than 16 in 1981-2. We again include in the specification the amount of land owned in the household, an indicator of land ownership, the average household endowment of other family members, and the child's age and age squared, but here the variables refer to the origin households in 1981-2. We use both GLS and GLLAM, making use of the four-round verification subsample in 1981-2.

The estimates of the effects of the body mass endowment on schooling completed by 2001-2 for boys and girls who were less than age 16 in 1981-2 are reported in Table 6. The results are consistent with the estimates obtained for contemporaneous school attendance: boys with a higher body mass endowment have fewer completed years of schooling in 2001-2 while larger girls attained marginally higher levels of schooling. The statistically significant errorcorrected point estimate indicates that boys whose body mass endowment is one standard deviation above the mean have almost one half a year less (0.48) schooling (12\%), while girls who are one standard deviation above the mean attain a (statistically insignificant) 0.2 more schooling years. 


\section{Body Mass Endowments and Occupational Sorting}

An important implication of the model is that not only does having an absolute advantage in brawn affect skill investment, but comparative advantage in brawn will affect the choice of tasks, with those individuals having relatively more brawn allocated to activities where brawn (schooling) has a higher (lower) relative payoff. To test this implication, we require, as for the index $i$ in the model, a ranking of activities by their brawn or skill intensity. One method for doing this would be to compute the fraction of high body mass men by occupation (or average body mass). However, this would be tautological. ${ }^{13} \mathrm{We}$ need to characterize the technology of tasks that is exogenous to the workforce that is in them. We could obtain estimates of the task production function parameters $\left(a_{i}\right)$ for each of the 34 activities/occupations in the data, taking into account optimal sorting. However, sample size, as well as tractability, precludes this approach. Instead we use information on the "energy requirements" of activities, compiled by the FAO and WHO (2001). This metric by design characterizes the intrinsic characteristics of the jobs and not the workers participating in them. We additionally assume that activities that require more energy expenditure per unit of time have a higher relative return to brawn and a lower return to skill. While we will formally test this assumption in the next section, it seems reasonable that brawn is more valuable in activities with higher occupational energy requirements in the rural context that we are examining in which most of the activities involve physical work. As seen in Table 1, almost two-thirds of men are involved in occupations in which brawn would appear a relevant task attribute. Using energy requirements as a singulate measure of relative occupation-specific returns to brawn or skill is not likely to be appropriate, however, in the context of a complex, industrialized economy where many non-physical attributes of workers are relevant to productivity and a worker's physical attributes for many jobs are irrelevant. ${ }^{14}$

The FAO defines the energy requirement of an activity as the amount of food energy that is required to maintain body size when participating in that activity. Physical activity rates (PAR's) are provided for each task, defined as the average energy expenditure per unit of time needed to carry out the task divided by the basal metabolic rate (energy expenditure at rest, BMR). The PAR for pulling a rickshaw with two passengers is 7.2, for example; that for weeding is 4.0 and the PAR's for sawing hardwood, bed making and filing or reading or writing are 6.6, 3.4 and 1.3, respectively. There is thus significant variation in energy expenditure across the physical activities of rural workers as well as across physical and non-physical activities. Moreover, the detailed time allocation information in the 2001-2 survey along with the detailed activities in the FAO compilation (e.g., bed making, fetching wood) enables us to compute the "occupational" energy expenditures associated with the specific activities of women who are not in the labor force. Because the PAR depends on the basal metabolic rate, which differs by gender and age, we use the adult, prime age PAR's

\footnotetext{
${ }^{13}$ As a first approximation, Thomas and Strauss (1997) stratify their sample of workers by education as a way of estimating the returns to health by occupation. The education of the actual workforce in an occupation, however, could not be used to test the role of comparative advantage in brawn or skill in occupational sorting.

${ }^{14}$ The 1977 United States Dictionary of Occupational Titles provides 38 categories of occupational attributes for 12,000 occupations. These include in addition to physical strength requirements, for example, eleven types of aptitude, temperament, and vocational training and educational requirements. Rendall (2010) uses factor analysis to reduce the set of 38 occupation characteristics for the United States to three, one of which is brawn.
} 
and calculate energy expenditures for each of the activities in our data by multiplying the PAR by the adult male BMR (65), expressed as kilojoules per hour, for both men and women. The occupational energy expenditure variable is thus an occupational index, and is inversely related to $a(i)$ in the model. Based on the model, we would expect that men with a higher body mass endowment would participate in higher energy expenditure (low $i$ ) tasks. Among women, however, for whom body mass does not translate into brawn, to the extent that body mass (greater health) augments skill acquisition, as we have seen at least marginally with respect to schooling, we should see a negative relationship between body mass and occupational energy expenditure (inclusive of home tasks).

Table 7 reports the GLS and GLLAM estimates of the relationships between the body mass endowment and occupation selection for men and women aged 20-49 in 2001-2, as measured by the occupational energy expenditure variable. An important constraint on occupational choice in Bangladesh is land ownership. Because those not owning land are less likely to cultivate, ${ }^{15}$ we include the size of owned landholdings and an indicator for the absence of any owned land in the occupation choice specification, along with the average body mass endowments for other family members to capture intrahousehold resource allocations. The estimates indicate that, while measurement error in the endowment variable evidently significantly negatively biases the coefficient on body mass, men with a higher body mass endowment choose occupations with significantly higher average energy requirements while women with a higher body mass endowment are over-represented in lower energy-expenditure activities, consistent with the model and the findings that schooling and body mass are negatively correlated for men and weakly positively correlated for women.

The coefficients on the land ownership variables are also consistent with the schooling results and with expectations for a rural setting, where, according to the FAO, energy expenditures are higher for farm worker activities than for farm management activities. The estimates indicate that for both men and women having no land is associated with activities having higher energy requirements, consistent with such individuals being primarily in wage worker activities and/or rickshaw pulling (for men). Occupational energy expenditure declines with land size, however, only for males. This is consistent with the schooling results in Tables 5 and 6, as males (but not females) from households with larger landholding are more likely to be in school and attain higher levels of schooling, for given body mass endowments. Men with larger landholdings are also more likely to be farm managers (no women are farm managers) and not farm workers. Interestingly, for given own body mass endowment, men but not women are less likely to be in higher energy-intensive activities if other household members have high endowments, suggesting within-household occupational diversification among men but not women. These findings thus suggest that both household characteristics and the endowed individual attributes of workers, in accord with their comparative advantage, sort individuals across activities. ${ }^{16}$

15 There is sharecropping in Bangladesh, so some cultivators do not own land.

16 That household attributes in addition to individual comparative advantage also matter for occupational sorting will be important in identifying activity-specific returns to brawn and schooling by activity that is a key assumption of the Roy-based model, as discussed below. 


\section{Alternative Interpretations and Threats to Identification}

Before proceeding to test the assumption that schooling and brawn returns differ across occupations, we consider two alternative explanations for why we find that males with larger body mass endowments obtain less schooling and enter into occupations where brawn is important while larger women obtain slightly more schooling and allocate themselves to less brawn-intensive activities. One alternative explanation to the productivity of brawn influencing allocation decisions is that body mass or brawn in fact has little productive value but is negatively correlated with "ability" - thus larger (less able) men attend school less and enter brawn-intensive activities not because they have a comparative advantage in brawn but because the only attribute that matters in the economy is cognitive ability and such men are simply less smart - a one factor model is capable of explaining the results. ${ }^{17}$ The second alternative explanation for the difference in findings for males and females is that body mass affects age at menarche for women, which is an important and unique determinant of girls' marriage age and schooling (Ambrose and Field, 2008).

We assess the alternative explanation that body mass is just an inverse correlate of cognitive ability in two ways. First, if body mass and ability are negatively correlated and brawn is relatively unproductive then the reduced-form relationship for men between the body mass endowment and wages should unambiguously be negative - we have seen that brawnier men have less schooling and by this hypothesis they are also less able. On the other hand, if brawn is productive, as assumed in the model, and independent of cognitive ability, then it must be true that men who are endowed with more brawn will have higher lifetime earnings than men with lower brawn, despite lower schooling, if schooling is chosen optimally. It is possible that wages are lower for brawnier men (who have a longer work span), but if it is found that such men earn higher wages then we can reject the hypothesis that brawn is just an inverse measure of ability. Second, we can directly test whether cognitive ability and body mass are correlated, by looking at the relationship between the body mass endowment and performance measures from the cognitive ability assessments carried out in the 2007-8 survey.

\section{A. Does brawn have a labor market payoff?}

The first two columns of Table 8 report the GLS and GLLAM reduced-form estimates, respectively, of the relationship between the body mass endowment and the log daily wage in 2001-2 for males aged less than 18 in 1981-2, again controlling for household characteristics in 1981-2. Consistent with the assumption of the model that brawn is productive and not just a negative correlate of ability, men with higher body mass endowments, once measurement error is taken into account, earn significantly higher wages, despite, as seen in Table 6, having lower schooling attainment. The error-corrected point estimate indicates that a one standard deviation increase in the body mass endowment increases the adult wage by $7.1 \%$.

In columns three through six we also explore the sensitivity of the schooling "return" estimates to the exclusion of brawn, using the conventional Mincer wage specification that

${ }^{17}$ Of course this cannot explain why females who have larger body masses do not reduce their schooling. 
is pervasive in the literature. The log-linear wage function estimate of the schooling return, with the body mass endowment excluded, is reported in the third column. The return is low at $2.6 \%$, but is measured with precision. In the fourth and fifth columns the body mass endowment is also included in the log wage specification, estimated using GLS and GLLAM, respectively. With or without measurement correction the inclusion of the brawn measure increases the estimated return to schooling, consistent with the finding that schooling and brawn are negatively correlated for men. The fifth-column results, which correct for measurement error, indicate that brawn net of schooling positively affects the wage. The estimates also suggest that by not considering how heterogeneity in brawn affects schooling attainment and wages, the estimated Mincer return to schooling is under-estimated by $16 \%$. "Brawn bias" thus can explain at least part of the gap in the estimated returns to schooling between men and women (when occupational sorting is ignored), given that body mass and schooling are not negatively correlated for women. Finally in the last column we allow for ability bias by instrumenting schooling, using the family background variables landholdings, land ownership and the household average endowment in $1982 .{ }^{18}$ The resulting GLLAM-IV schooling coefficient is higher than the GLLAM coefficient, indicating some positive ability bias. However, the positive body mass coefficient and its statistical significance are unchanged. Of course, the wage specification used here, which assumes there is a common schooling (and body mass) return, is inconsistent with the Roybased model. We obtain estimates of a wage function, in the last section of the paper, using the larger 2001-2 sample incorporating schooling, body mass, and occupation that is consistent with the Roy-type sorting model and that rejects the log-linear specification that assumes that returns are invariant across activities.

\section{B. Are bigger men, or women, dumber?}

The finding that the association between body mass and wages is positive net and gross of schooling attainment refutes the idea that body mass is merely a negative correlate of ability as an explanation for why larger males obtain less schooling. However, to the extent there is a correlation between cognitive ability and body size, the coefficient on body mass will not wholly reflect the effects of brawn, and it is not obvious how brawn and ability endowments are jointly distributed in the population. To directly assess whether body mass and ability are significantly correlated we estimated the association between a respondent's body mass endowment and his or her performance on the Raven's Abridged Matrices tests that were administered to all adult respondents in 2007-8.

Table 9 reports the GLS and GLLAM estimates, by gender, of the effects of the body mass endowment on the total number of correct answers (out of nine) for respondents aged 20-49 in 2001-2. The mean (standard deviation) number of correct answers was 3.66 (1.96) for men and 2.94 (1.73) for women, with the complete distribution of test scores by gender depicted in Figure A in the Appendix. The first two columns of Table 9 indicate that while larger men perform less well than smaller men, the point estimate is very small - a one standard deviation increase in the body mass endowment reduces the test score (total correct

${ }^{18}$ The first-stage estimates are similar to those reported in Table 6 for male schooling attainment. The only difference is that males aged less than 18 in 1981-2 are used rather than males aged less than 16. 
answers) by less than 3 percent (one tenth of a question). It is well recognized, however, that performance on the Raven's test, despite neither requiring literacy nor numeracy, is affected by schooling, and larger men have less schooling. When schooling attainment is included in the specification in column 3 its coefficient is indeed highly statistically significant and positive. Moreover, the coefficient on the body mass endowment is reduced by more than an order of magnitude to essentially zero. Evidently, larger men, net of schooling, are no less able to carry out mental tasks than are men with less brawn.

For women, the reduced-form relationship between the body mass endowment and test score performance is positive and marginally statistically significant when measurement error is taken into account (column 5). However, as for men, schooling and test scores are strongly positively correlated (column 6) and the effect of body mass on the test score is not statistically significant when schooling attainment is included in the specification. Although still positive, the point estimate is also small - a one-standard deviation increase in body mass for women, net of schooling, increases the number of correct answers by less than a tenth $(3.1 \%)$. Interestingly, when schooling is included in the specification, the association between landholdings and test performance is also eliminated for both men and women larger landowners do not perform better on the test once their higher level of schooling is taken into account.

\section{Age at menarche and the body mass endowment}

Ambrose and Field (2008) show that age at menarche is a strong predictor of completed schooling for women in Bangladesh because it affects when they marry. If age at menarche is higher for women with a larger body mass endowment, this could explain the sign reversal, relative to men, for the estimated body mass effects on schooling. The medical literature, however, suggests that age at menarche is negatively related to body mass in poor countries (Khah et al., 1995), including specifically Bangladesh (Bosch et al., 2008). We can use our panel data to estimate directly the association between the body mass endowment and age at menarche. Women were asked in the 2001-2 survey to provide their age at menarche. Among women in the 2001-2 sample who were aged less than 13 in 1981-82 for whom we have nutritional intake information and information on parental landholdings, menarche was at age 12 or less for $21.3 \%$, at age 13 for $54.8 \%$, at age 14 for $21.8 \%$ and at age 15 or above for $2.0 \%$ of the sample.

The first two columns of Table 10 report logit and logit GLLAM estimates, respectively, of the effects of the body mass endowment for girls aged less than age 14 in 1981-2 on the probability that age at menarche occurred after age 13 (delayed menarche) as reported in 2001-2. As can be seen, girls with a larger body mass, consistent with the medical literature, were statistically significantly less likely to have a delayed age at menarche. The errorcorrected point estimate indicates that a one standard deviation in the body mass endowment reduces the probability of menarche after age 13 by 11 percentage points, and the estimates are evidently robust to the inclusion of controls for cohort (age) or family landholdings, as seen in columns three and four of the table. These results thus indicate that the relationship between body mass and menarche cannot be the reason for the positive association between schooling and body mass among women. Indeed, the estimates in Table 10 suggest that the 
positive effect of body mass on schooling for women may be underestimated given the marriage practices tied to age at menarche in Bangladesh - higher body mass women are more likely to marry earlier and thus truncate their schooling.

\section{Estimating the "Roy" Wage Function}

The finding that the body mass endowment differentially affects the choice of activities for women and men is consistent with the assumption of the Roy model that occupations reward worker attributes differently, but it could also reflect other factors such as discrimination and/or tradition. In this section we directly test the assumption that high-energy expenditure occupations reward brawn relative to skill by estimating a wage function that is consistent with, and derived from, the Roy-based model in which workers have two productive attributes, brawn and skill, the returns to the attributes differ across tasks, and there are optimal investments in skill via schooling. The wage function for a worker $j$ in activity $i$ from the model, with an appended individual worker productivity error term $\xi$, from (1), is:

$$
W(i)_{j}=\pi(i) \kappa(i)\left(v H_{j}\right)^{\alpha(i)} B_{j}^{(1-\alpha(i))} \xi_{j}
$$

There are a number of challenges in estimating the parameters describing (24). First, brawn and skill are not directly observed, so we need to express these attributes in terms of the observables schooling and the body mass endowment. That is we need to incorporate in (24) the production functions (2), (3) and (4) that relate brawn to the body mass endowment $m$ and skill to schooling $S$. Second, returns $(a(i))$ differ by activity. Third, both schooling and activity $i$ are optimally chosen so that they may be related to the unobservable component of productivity $\xi$, which may contain the unobservable ability of the worker. And fourth, the body mass endowment contains measurement error. To estimate (24) we therefore need to impose additional structure. We now formally assume that skill-intensity $a(i)$ is inversely related to the energy expenditure $\varepsilon(i)$ of an occupation by assuming that $a(i)=a_{0}+a_{1} \varepsilon(i)$, with $a_{0}>0$ and $a_{1}<0$. In the model the duple $\pi(i) \kappa(i)$ varies by activity in equilibrium; accordingly we assume that $\pi(i) \kappa(i)$ is also a function of $\varepsilon(i)$, such that $\pi(i) \kappa(i)=\varepsilon(i) \delta$. We also assume that the skill and brawn production functions are exponential, such that $H_{j}=$ $\mathrm{e}^{\beta S(j)}$ and $B_{j}=\mathrm{e}^{\gamma m(j)}$, where $\beta>0$ and $\gamma>0$.

Replacing the unobservable price, brawn and skill terms by the observables $\varepsilon(i), m_{j}$, and $S_{j}$ using the production function relationships and taking logs yields the estimable wage function in terms of the structural parameters:

$$
\log W(i)_{j}=\delta \log \varepsilon(i)+\alpha_{0} \beta S_{j}+\alpha_{1} \varepsilon(i) \beta S_{j}+\left(1-\alpha_{0}\right) \gamma m_{j}-\alpha_{1} \varepsilon(i) \gamma m_{j}+\log \xi_{\mathrm{j}},
$$

The corresponding estimating equation is:

$$
\log W(i)_{j}=\delta \log \varepsilon(i)+v_{1} S_{j}+v_{2} \varepsilon(i) S_{j}+v_{3} m_{j}-v_{4} \varepsilon(i) m_{j}+\log \xi_{\mathrm{j}}
$$


where the $v$ are coefficients. The only structural parameter that is identified from the estimation of (26) is $\delta$, although we cannot distinguish between changes in product prices $\pi$ and changes in overall activity productivity with brawn-intensity Recall, however, that the sign of $\delta$, from (10), indicates whether workers in the economy have a comparative advantage in brawn (e.g., $\delta<0$ if $\log (v B / H)<0$ ). The model, given our assumptions, also places sign restrictions on three of the coefficients; in particular, $v_{1}>0, v_{2}<0$, and $v_{4}>0$ - the "return" to schooling, $v_{1}+v_{2} \varepsilon(i)$, should be lower in energy (brawn)-intensive activities and the return to brawn should be higher in energy-intensive activities. Note that the log-linear wage function, which imposes the restrictions that $v_{2}=0$ and $v_{4}=0$, is nested in (26).

To take into account that the body mass endowment is measured with error and that schooling and activity choice may be related to $\xi$, we use GLAMM-IV to estimate (26), making use of the repeated measures of $m_{j}$ from the verification subsamples and using the household characteristics landholdings and the endowments of other family members as identifying instruments. The estimates of schooling attainment and choice of activity, in Tables 6 and 7, suggest that household variables affect schooling and activity choices in addition to the body mass endowment. These variables should not directly affect a worker's productivity, given his skill and brawn. Note that if activity choice was strictly based on individual comparative advantage and schooling investment depended only on $m_{j}$ it would not be possible to estimate $v_{2}$ and $v_{4}$ because $S$ and $m$ would covary perfectly within occupations. That activity choices and schooling investments are constrained by household attributes aids identification. ${ }^{19}$

We estimate (26) for males aged 20-49 in 2001-2. ${ }^{20}$ Table A in the appendix reports the first-stage estimates of the determinants of the activity choice (occupational energy expenditure), schooling and interaction variables of schooling, the body mass endowment and occupational energy expenditure. In all cases the $F$-statistics indicate that the set of instruments contribute significantly to accounting for the variation in the endogenous variables, consistent with our earlier findings. Table 11 reports the estimates of the log wage coefficients. In the first column, the estimate of the schooling coefficient using the standard Mincer specification, in which only schooling and age and age squared are included, is reported. The Mincer schooling return is $4.1 \%$. The second column reports estimates from a log-linear specification which includes both schooling and the (error-corrected) body mass endowment. The endowment has a positive but statistically insignificant effect on the log wage and the schooling coefficient rises by only a small amount. The weak performance of the body mass endowment is in accord with the findings in Behrman et al. (2009), who also employ a specification log-linear in schooling and health and find weak health effects. In the third column the estimated coefficients from the full, Roy-model consistent specification that allows returns to differ by occupation is estimated, but without using IV. The coefficient patterns are in conformity with the model - the schooling return is lower and the endowment

\footnotetext{
${ }^{19}$ We derive second-stage coefficient standard errors using boostrapping.

${ }^{20}$ Less than $17 \%$ of males in this age group do not report wage earnings. However, less than $20 \%$ of females in this age group work for wages, so we do not attempt to estimate the wage functions for women. Note that the model implies that the parameters of the wage function (26), which take into account differences in activity-specific valuations of worker attributes, should be the same for men and women; the estimates of returns to schooling in the literature differ by gender because the wage functions that are estimated assume attribute-specific returns are identical across activities and differences in occupational distributions by gender are irrelevant.
} 
return higher in the energy-intensive activities. The set of body mass endowment coefficients is now statistically significant; in contrast to the linear specification estimates, body mass matters for productivity.

The last column of Table 11 reports the statistically-preferred coefficients obtained using instrumental variables. The coefficient sign patterns are the same as those estimated without instruments, indicating that schooling returns decline and body mass returns increase as the energy expenditure of an occupation rise, but now all of the interaction and linear coefficients are individually statistically significant. The log-linear specification, augmented or not with health, is rejected. The point estimates from the full specification indicate that the returns to schooling are positive only in the least energy-intensive activities, those associated with relatively sedentary activities engaged in by clerks and tailors. These activities make up a small proportion of total activities in the rural setting, but they are occupations in which women are over-represented relative to men. The return to body-mass, however, is positive for activities engaged in by $64 \%$ of male workers. Consistent with these findings, the estimate of $\delta$ is negative - high energy-intensive activities are valued less than low energy-intensive activities, implying that male workers in rural Bangladesh have a comparative advantage in brawn. The estimates and the distribution of workers among activities are indeed consistent with rural Bangladesh being a brawn-based economy.

\section{Conclusion}

An emerging set of studies suggests that the returns to investments in schooling and health differ across males and females in a variety of settings. In particular, health investments augment the schooling of women relative to men, but increase the earnings of men relative to women, while schooling has greater labor-market returns for women. Moreover, in an increasing number of countries, both developed and low-income, women acquire greater amounts of schooling than do men. In this paper we have used a simple model of human capital investment and activity choice to explain these findings. The model incorporates gender differences in the level and responsiveness of brawn to nutritional intakes in a setting in which activities reward skill and brawn differentially. Empirical evidence from rural Bangladesh, where brawn plays a prominent role in economic activities, appears to support the model and the importance of the distribution of brawn in explaining gender differences in human capital investments and returns.

The estimates indicate that, consistent with the Roy model, returns to schooling and brawn differ significantly by occupation, with brawn-intensive activities rewarding skill less, and occupational selection is explained in part by individual comparative advantage in brawn. We find that because men have a comparative advantage in brawn, men obtain less schooling and sort into activities with lower returns to skill (and higher rewards for brawn) than do women. Our estimates also indicate that nutritional investments, because they augment the brawn of men, directly raise the wages of men. This increases the opportunity cost of schooling and makes it less profitable for men to enter into activities where schooling has high payoffs, so that despite schooling and health being complements in a technical sense, optimal schooling for men either does not increase or actually falls, as in our setting, when there are interventions that augment health. Among women, however, because 
strength does not increase significantly when there are improvements in health, schooling is positively affected by health gains because of this complementarity.

Our findings also suggest that log wage equations linear in human capital variables can hide important effects of health variation and cannot account for gender differences in returns. The estimated average return to schooling in an economy will importantly depend on the composition of activities and also on the correlation between health and schooling, which we show differs by gender. In brawn-based economies, for example, the average payoffs to schooling will be low but will be higher for women, who specialize in skill-intensive activities, while returns to health may be high for men but not women depending also on the mix of activities in the economy.

Our findings suggest how development policies will affect gender differences in earnings and schooling investment. For example, many development economists argue that investments in health are critical for development. Attention to the role of brawn suggests that health-based development, similar to the experience in Bangladesh, will, in the absence of any other changes, increase the schooling of women relative to men, increase occupational differentiation by gender and thus differences in returns to schooling by gender, but increase the gap in earnings between men and women. Similarly, a policy that favors agricultural development - a sector in which brawn has relatively high payoffs - will augment the earnings of men, who have an absolute advantage in brawn, relative to women and increase the gender division of labor across activities. In contrast, a policy promoting openness to trade and foreign investment that changes the occupational mix in favor of jobs that are skill-intensive will augment the earnings of women relative to men, increase schooling investments by women relative to men, and lower the gap in schooling returns. Given the distribution in brawn between men and women, however, to the extent that brawn-intensive occupations do not disappear returns to schooling and levels of schooling will in equilibrium be higher for women than for men in almost all economies.

In future work it would appear useful to consider the general-equilibrium effects of health investments and other development polices on activity prices and on the returns to brawn and skill. For example, the new brawn acquired through public health interventions should lower the overall return to brawn in the aggregate economy and thus possibly narrow the earnings gap between men and women. A limitation of our empirical analysis is that, because few women earn wages in our data, it was not possible to test a feature of the model that once occupational sorting is taken into account the parameters of the wage functions are identical by gender. Although we were able to estimate the relationship between body mass and a direct measure of one form of productivity, strength, for both men and women it would also be useful in future work to examine the payoffs to health and schooling investment in the marriage market and to account for marital as well as occupational sorting by brawn and skill.

\section{Acknowledgments}

The research for this paper was supported in part by NIH grant 5R01DK072413. 


\section{Figure A}

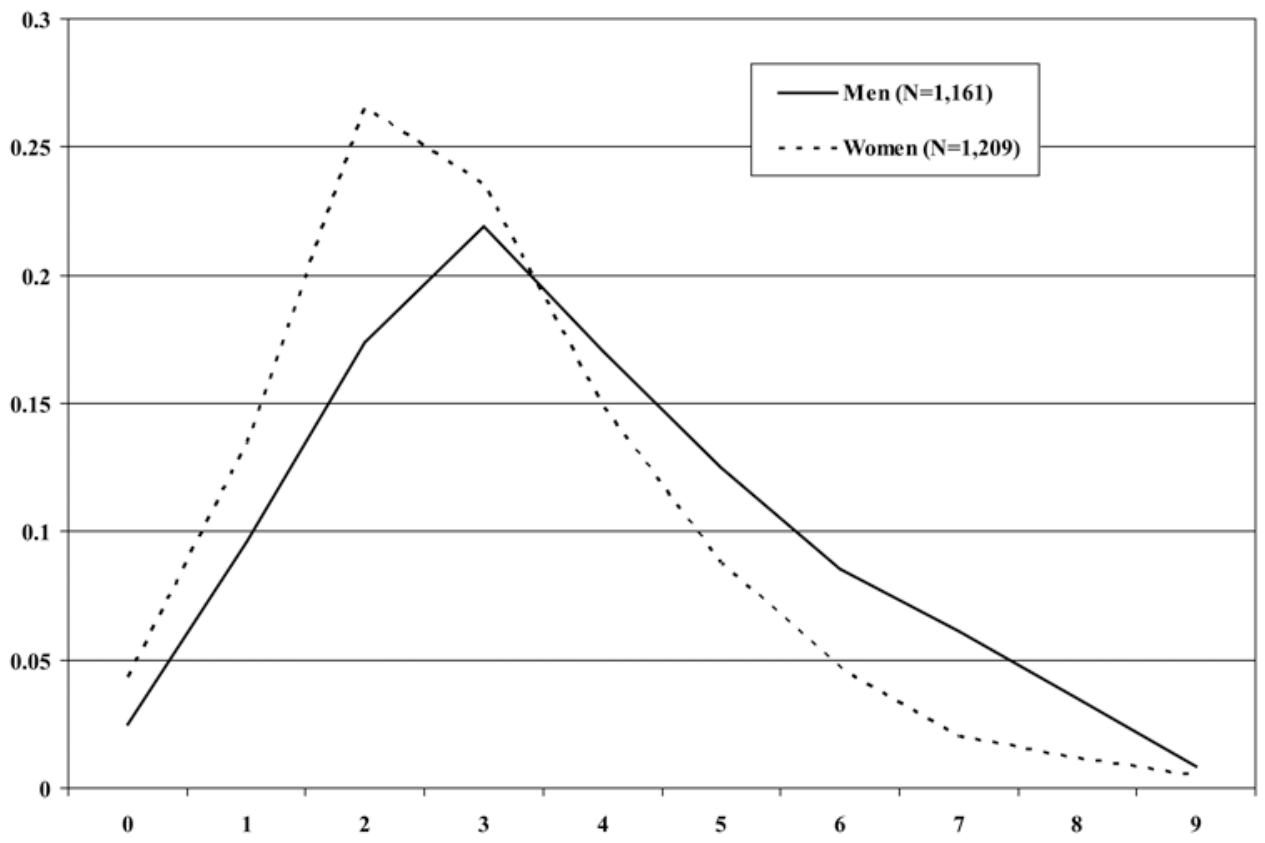

Distribution of Abridged Raven's Color Matrices Test Results by Gender: Number of Correct Answers, Respondents Aged 20-49

\section{Appendix Table A}

First-Stage Estimates for the Occupation-Specific Wage Function: Men Aged 20-49 in 2001-2

\begin{tabular}{|c|c|c|c|c|}
\hline Dependent variable: & Schooling (years) & $\begin{array}{c}\text { Schooling } \times \\
\text { occupational } \\
\text { energy } \\
\text { expenditure }\end{array}$ & $\begin{array}{c}\text { Endowment } \times \\
\text { occupational } \\
\text { energy } \\
\text { expenditure }\end{array}$ & $\begin{array}{c}\text { Log occupational } \\
\text { energy } \\
\text { expenditure }\end{array}$ \\
\hline Household owned land & $.00779(8.98)$ & $.943(7.93)$ & $-.00568(2.87)$ & $-.000237(4.76)$ \\
\hline No land owned & $-.815(2.89)$ & $-92.6(2.40)$ & $2.54(3.82)$ & $.0373(2.29)$ \\
\hline Endowment & $-1.57(2.48)$ & $-105.4(1.22)$ & $174.6(113.5)$ & $.534(14.6)$ \\
\hline $\begin{array}{l}\text { Household average endowment } \\
\text { of other family members }\end{array}$ & $2.39(3.08)$ & $208.8(1.96)$ & $-7.27(3.93)$ & $-.140(3.12)$ \\
\hline Age & $.131(0.92)$ & $12.6(0.65)$ & $-.291(0.84)$ & $-.00147(0.18)$ \\
\hline Age squared & $-.00207(1.02)$ & $-.184(0.67)$ & $.00452(0.92)$ & $.0000817(0.70)$ \\
\hline$F(19,1022)$ & 15.3 & 13.0 & 176.2 & 20.6 \\
\hline $\begin{array}{l}F(3,1022) \text { : land, no land, } \\
\text { average household endowment }\end{array}$ & 33.1 & 27.0 & 18.4 & 17.0 \\
\hline $\begin{array}{l}F(16,1022) \text { : land, no land, } \\
\text { average household endowment } \\
+ \text { village fe }\end{array}$ & 15.3 & 14.0 & 6.35 & 7.83 \\
\hline $\mathrm{N}$ & 1,094 & 1,094 & 1,094 & 1,094 \\
\hline
\end{tabular}

Source: NSRB 2001-2. Absolute values of asymptotic $t$-ratios corrected for clustering within households in parentheses in column. All specifications include village fixed-effects. 


\section{References}

Bangladesh Bureau of Educational Information and Statistics. Bangladesh Educational Statistics 1987, 1991, 1997, 2003. 1987, 1991, 1998, 2003

Behrman, JereR; Hoddinott, James; Maluccio, JohnA; Martorell, Reynaldo. Brains versus Brawn: Labor Market Returns to Intellectual and Health Human Capital in a Poor Developing Country. Middlebury College Discussion Paper No 0907. 2009

Bosch AM, Willekens FJ, Baqui AH, Van Ginneken JKS, Hutter I. Association between Age at Menarche and Early-Life Nutritional Status in Rural Bangladesh. Journal of Biosocial Science. 2008; 40(2):223-237. [PubMed: 17956652]

Dougherty, Christopher. Why Are the Returns to Schooling Higher for Women than for Men? The Journal of Human Resources. 2005; 40(4):969-988.

Field, Erica; Ambrus, Attila. Early Marriage, Age at Menarche and Female Schooling Attainment in Bangladesh. Journal of Political Economy. 2008; 116(5):881-930.

Food and Agriculture Organization of the United Nations. Human Energy Requirements Report of a Joint FAO/WHO/UNU Expert Consultation. Rome: FAO Food and Nutrition Technical Report; 2001. p. 1-96.1

Gersovitz, Mark. Savings and Nutrition at Low Incomes. The Journal of Political Economy. 1983; 91(5):841-855.

Glewwe, Paul; King, ElizabethM. The impact of early childhood nutritional status on cognitive development: Does the timing of malnutrition matter? The World Bank Economic Review. 2000; 15(1):81-113.

Günther, ChristianM; Bürger, Alexander; Rickert, Markus; Crispin, Alexander; Schulz, ChristophU. Grip Strength in Healthy Caucasian Adults: Reference Values. Journal of Hand Surgery. 2008; 33:558-565. [PubMed: 18406961]

Heckman, JamesJ; Sedlacek, Guillermo. Heterogeneity, Aggregation, and Market Wage Functions: An Empirical Model of Self-Selection in the Labor Market. Journal of Political Economy. 1985; 93(6):1077-1125.

Hels O, Hassan N, Tetens I, Haraksingh Thilsted S. Food Consumption, Energy and Nutrient Intake and Nutritional Status in Rural Bangladesh: Changes from 1981-1982 to 1995-1996. European Journal of Clinical Nutrition. 2003; 57:586-594. [PubMed: 12700621]

Hoddinott, James; Maluccio, JohnA; Behrman, JereR; Flores, Rafael; Martorell, Reynaldo. Effect of a Nutrition Intervention during Early Childhood on Economic Productivity in Guatemalan Adults. The Lancet. 2008; (371):411-416.

Hogan, MargaretC; Foreman, KyleJ; Naghavi, Mohsen; Ahn, StephanieY; Wang, Mengru; Makela, SusannaM; Lopez, AlanD; Lozano, Rafael; Christopher, J.; Murray, L. Maternal Mortality for 181 Countries, 1980-2008: a Systematic Analysis of Progress Towards Millennium Development Goal 5. The Lancet. 2010; (375):1609-1623.

Jayachandran, Seema; Lleras-Muney, Adriana. Life Expectancy and Human Capital Investments: Evidence from Maternal Mortality Declines. The Quarterly Journal of Economics. 2009; 124(1): 349-397.

Khah, AwalD; Schroeder, DirkG; Martorell, Reynoldo; Rivera, JuanA. Age at Menarche and Nutritional Supplementation. The Journal of Nutrition. 1995; (Supplement):1090S-1096S. [PubMed: 7722711]

Khandker, ShahidurR; Pitt, MarkM; Fuwa, Nobuhiko. Subsidy to Promote Girls' Secondary Education: The Female Stipend Program in Bangladesh. mimeo. 2003

Maluccio, John; Hoddinott, John; Behrman, JereR; Martorell, Reynoldo; Quisumbing, AgnesR; Stein, AryehD. The Impact of Improving Nutrition During Early Childhood on Education among Guatemalan Adults. The Economic Journal. 2009; 119(537):734-763.

Virgil, Mathiowetz; Kashman, Nancy; Volland, Gloria; Weber, Karen; Dowe, Mary; Rogers, Sandra. Grip and Pinch Strength: Normative Data for Adults. Archives of Physical Medicine and Rehabilitation. 1985; 66:69-72. [PubMed: 3970660]

Miguel, Edward; Kremer, Michael. Worms: Identifying Impacts on Education and Health in the Presence of Treatment Externalities. Econometrica. 2004; 72(1):159-217. 
Franziska, Ohnsorge; Trefler, Daniel. Sorting It Out: International Trade with Heterogeneous Workers. Journal of Political Economy. 2007; 115(5):868-892.

Pitt, MarkM; Rosenzweig and Nazmul Hassan, MarkR. Productivity, Health, and Inequality in the Intrahousehold Distribution of Food in Low-Income Countries. The American Economic Review. 1990; 80(5):1139-1156.

Psacharopoulos, George; Anthony Patrinos, Harry. Returns to Investment in Education: a Further Update. Education Economics. 2004; 12(2):111-134.

Rabe-Hesketh, Sophia; Skrondal, Anders; Pickles, Andrew. Maximum Likelihood Estimation of Generalized Linear Models with Covariate Measurement Error. The Stata Journal. 2003; 3(4):386411.

Rahman, RushidanIslam. An Analysis of Real Wage in Bangladesh and Its Implications for Underemployment and Poverty. Bangladesh Insitute of Deevlopment Studies, mimeo; 2009.

Ravallion, Martin; Wodon, Quentin. Does Child Labour Displace Schooling? Evidence on Behavioral Responses to an Enrollment Subsidy. The Economic Journal. 2000; 110:158-175.

Rendall, Michelle. Brain versus Brawn: The Realization of Women's Comparative Advantage. mimeo; 2010.

Round JM, Jones DA, Honour JW, Nevill AM. Hormonal Factors in the Development of Differences in Strength between Boys and Girls during Adolescence: A Longitudinal Study. Annals of Human Biology. 1999; 26(1):49-62. [PubMed: 9974083]

Roy AD. Some Thoughts on the Distribution of Earnings. Oxford Economic Papers. 1951; 3:135-146.

Thomas, Duncan; Strauss, John. Health and Wages: Evidence on Men and Women in Urban Brazil. Journal of Econometrics. 1997; 77(1):159-185. [PubMed: 12292719]

Trostel, Philip; Walker, Ian; Woolley, Paul. Estimates of the Economic Return to Schooling for 28 Countries. Labour Economics. 2002; 9(1):1-16. 
Distrbution of Dynamo meter G ip Stie ngth Test Results by Gender (Mathiowetz et al (1985)k: Pounds of Press ure, U. S Respond ents A ged 20-9 4
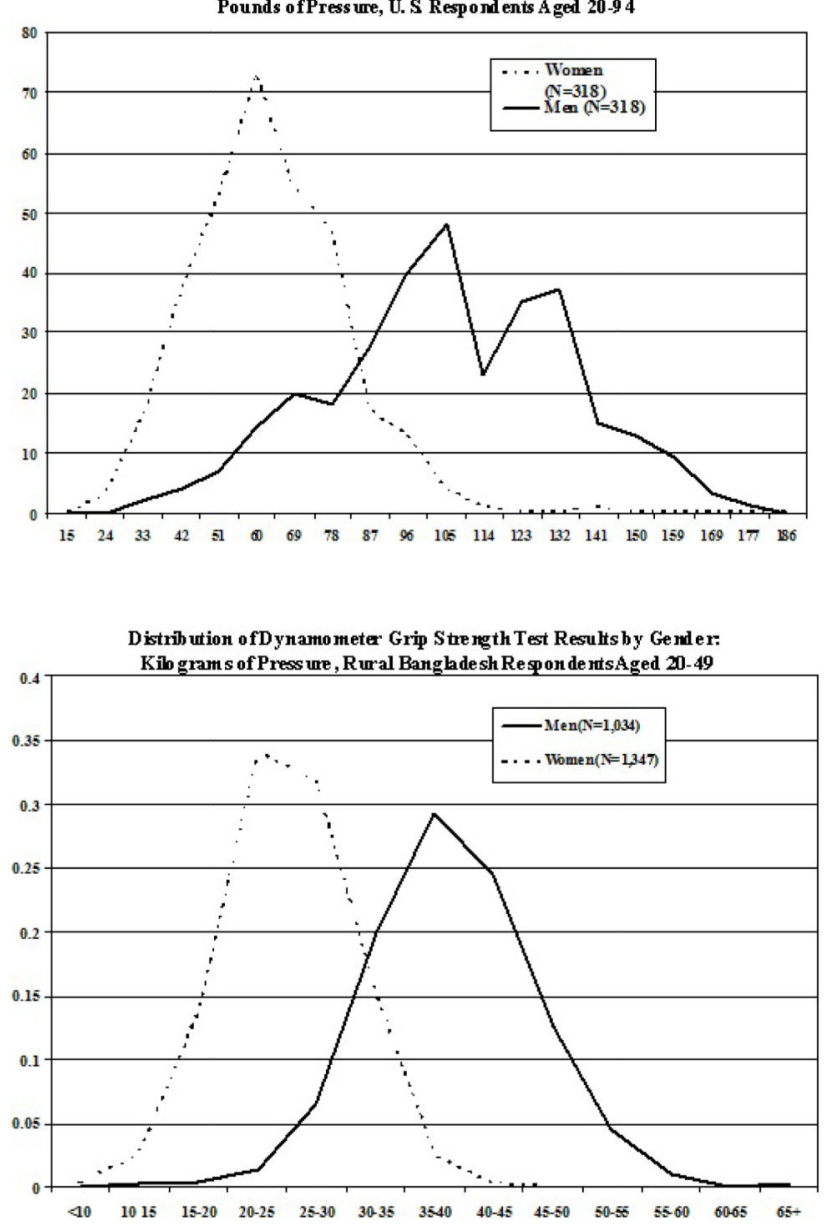

Figure 1. 


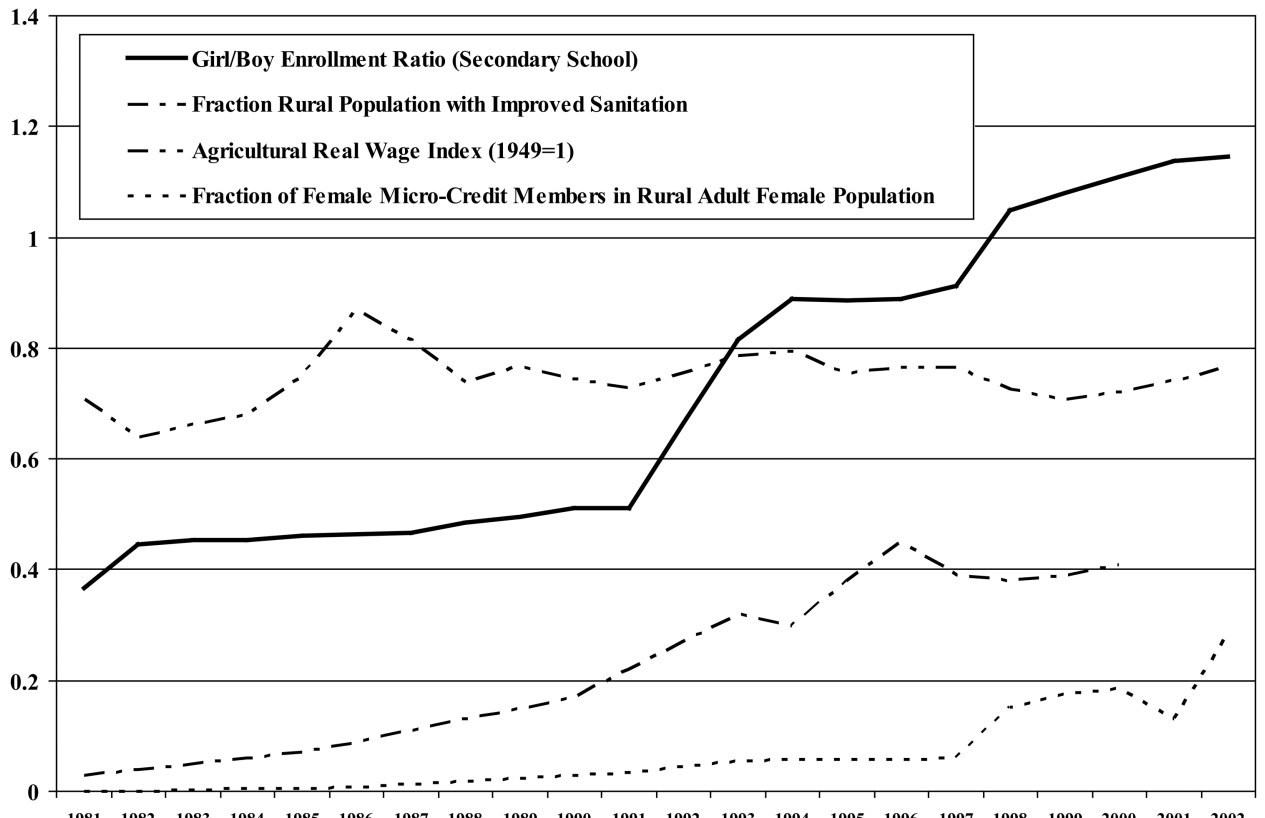

$\begin{array}{lllllllllllllllllllllll}1981 & 1982 & 1983 & 1984 & 1985 & 1986 & 1987 & 1988 & 1989 & 1990 & 1991 & 1992 & 1993 & 1994 & 1995 & 1996 & 1997 & 1998 & 1999 & 2000 & 2001 & 2002\end{array}$

Figure 2. Rural Bangladesh 1981-2002: Ratio of Girls to Boys Enrolled in Rural Secondary Schools, Real Agricultural Wage Index, Fraction of Rural Population with Improved Sanitation, and Fraction of Adult Women Belonging to Micro-Credit Groups 


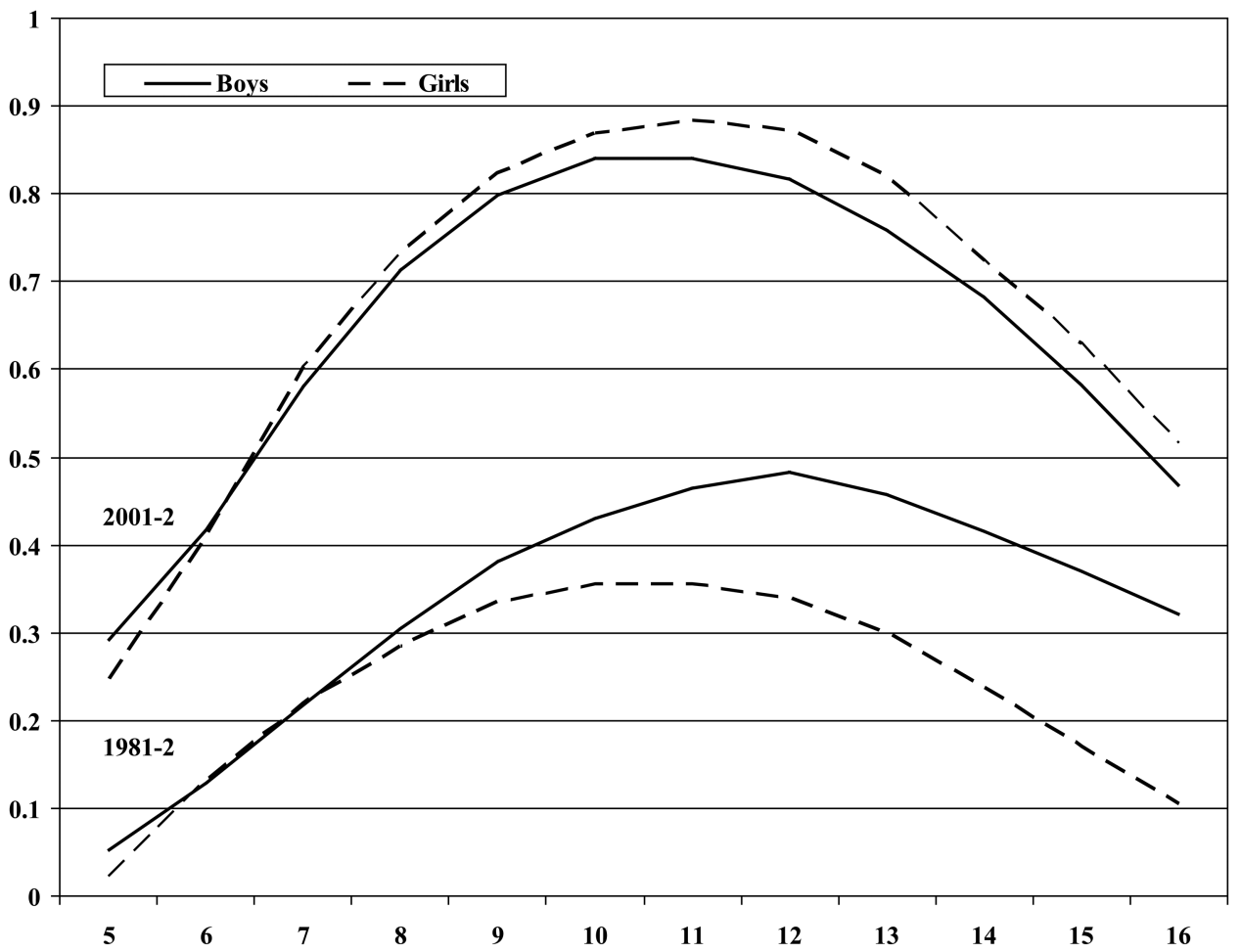

Figure 3. School Attendance, by Age, Gender and Survey Year 

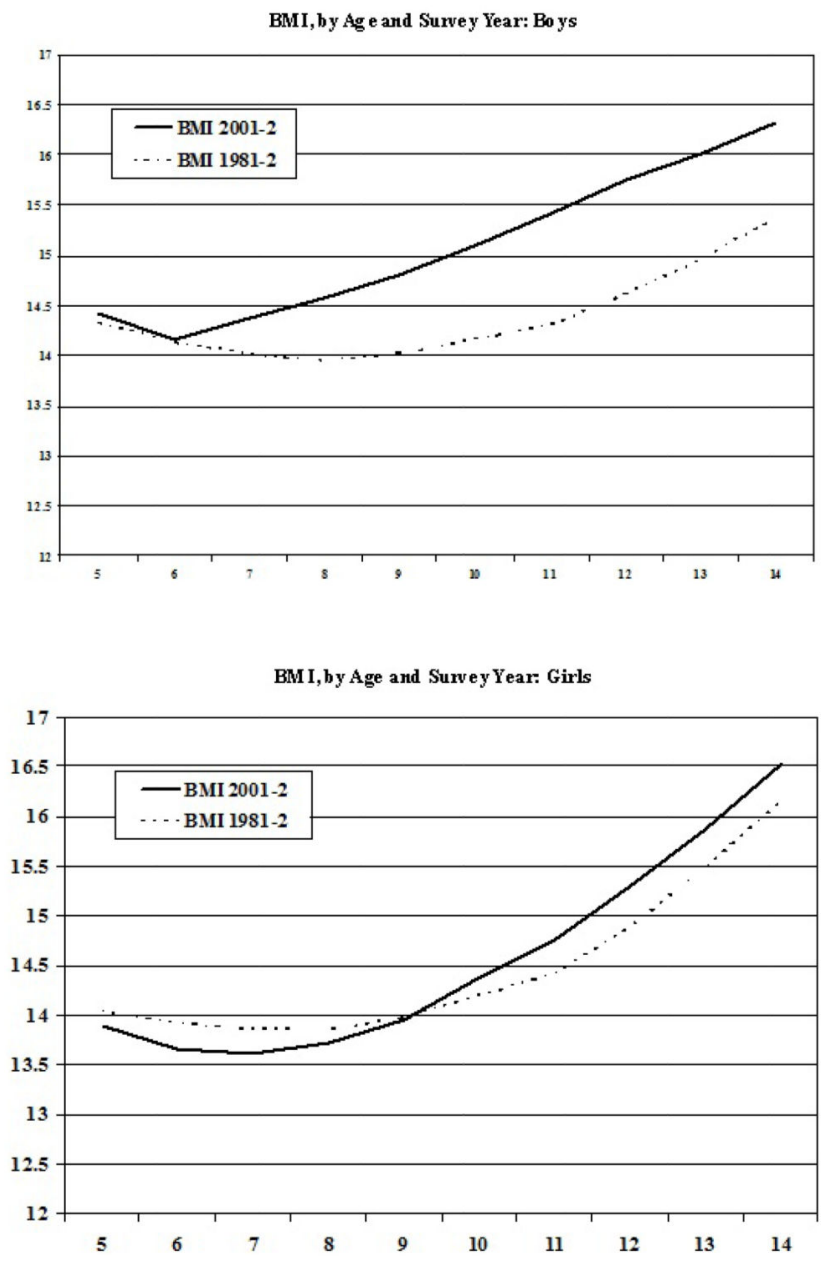

Figure 4. 

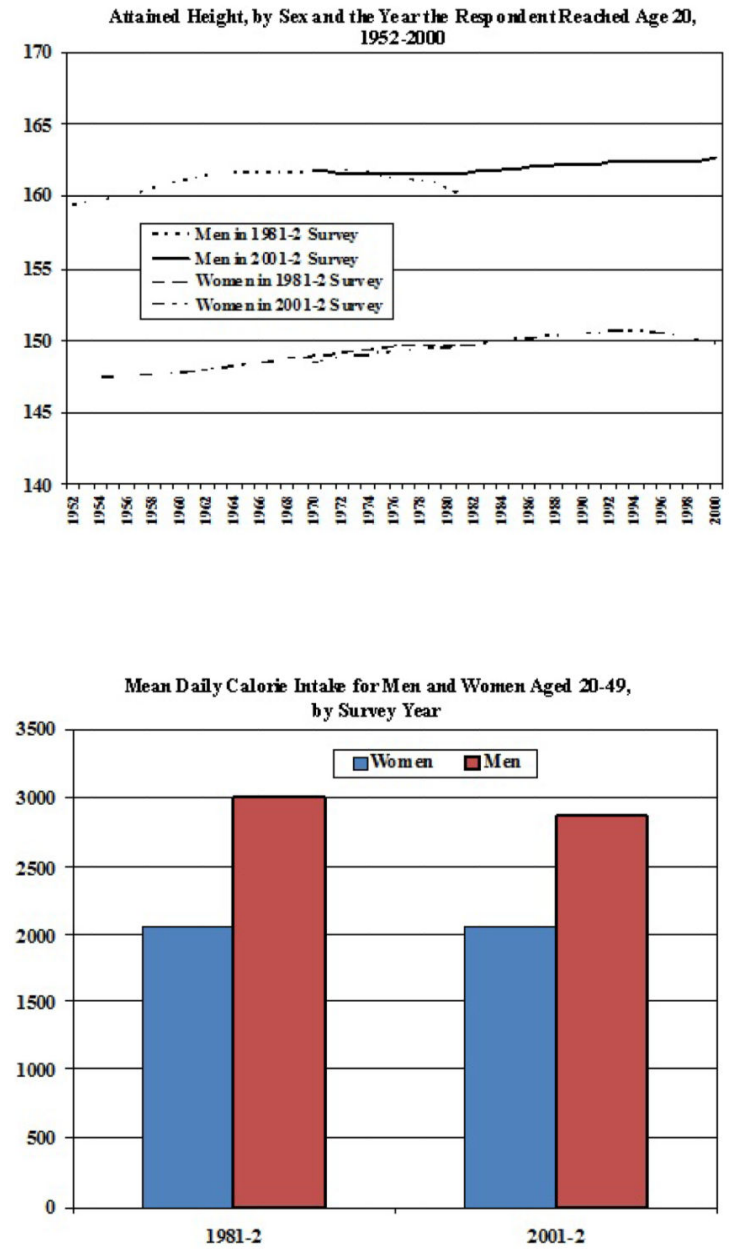

Figure 5. 
Table 1

Occupational Distributions in Bangladesh in 2004, by Gender and Rural-Urban

\begin{tabular}{|c|c|c|}
\hline Occupation/Population & Rural & Urban \\
\hline \multicolumn{3}{|l|}{ Men } \\
\hline Farmer, agricultural laborer, fisherman & 49.4 & 9.7 \\
\hline Unskilled laborer (rickshaw puller, brick breaking, etc.) & 12.0 & 14.8 \\
\hline Factory worker or blue-collar service & 3.3 & 7.5 \\
\hline Semi-skilled laborer (carpenter, mason, bus/taxi driver) & 9.8 & 22.4 \\
\hline Professional (teacher, doctor, lawyer) & 2.4 & 5.2 \\
\hline Business & 16.4 & 31.3 \\
\hline Other & 0.6 & 0.4 \\
\hline Not working & 5.8 & 8.7 \\
\hline \multicolumn{3}{|l|}{ Women } \\
\hline Agricultural worker & 1.2 & 0.4 \\
\hline Home-based manufacturing & 3.7 & 3.1 \\
\hline Unskilled laborer (construction, brick breaking, etc.) & 2.7 & 2.4 \\
\hline Poultry raising, cattle raising, trading & 7.8 & 3.5 \\
\hline Domestic labor & 2.0 & 5.8 \\
\hline Semi-skilled service (tailor, etc.) & 3.0 & 6.4 \\
\hline Professional (teacher, doctor, lawyer) & 0.5 & 1.7 \\
\hline Business & 1.7 & 2.3 \\
\hline Other & 0.9 & 1.8 \\
\hline Not working & 76.3 & 72.6 \\
\hline
\end{tabular}

Source: Bangladesh: Demographic and Health Survey, 2004 
Table 2

2SLS Estimates of the (Cobb-Douglas) Body-Mass Production Function, by Survey Population

\begin{tabular}{|c|c|c|}
\hline \multicolumn{3}{|l|}{ Dependent variable: log weight/height } \\
\hline Input/Survey population & $1981-2^{b}$ & 2001-2 \\
\hline Log individual total calorie consumption ${ }^{a}$ & $.136(3.37)$ & $.241(3.76)$ \\
\hline Very active occupation ${ }^{a}$ & $-.0119(0.23)$ & $-.0445(3.20)$ \\
\hline Exceptionally active occupation ${ }^{a}$ & $-.0817(1.26)$ & $-.125(5.65)$ \\
\hline Pregnant ${ }^{a}$ & $.326(1.34)$ & $.0273(1.33)$ \\
\hline Lactating $^{a}$ & $.513(4.65)$ & $.0339(1.39)$ \\
\hline Log age & $.0987(1.90)$ & $.00804(9.02)$ \\
\hline Log age squared & $.0174(2.37)$ & $-.000092(8.86)$ \\
\hline Male & $-.0578(1.81)$ & $-.00947(2.89)$ \\
\hline Male*log age & $.0687(4.04)$ & $.00116(3.72)$ \\
\hline Water drawn from tube well & $-.0406(2.10)$ & $.00551(0.88)$ \\
\hline Water drawn from well & $-.0693(3.15)$ & $.00118(0.18)$ \\
\hline Water drawn from pond & $-.0649(2.55)$ & $.0216(2.36)$ \\
\hline $\mathrm{N}$ & 1,737 & 5,750 \\
\hline $\begin{array}{l}\mathrm{H}_{\mathrm{g}} \text { : calories, age, age squared, male, exceptionally active, very active, male*age }=\text { across populations; } \chi^{2}(7) \\
(p)\end{array}$ & 9.0 & $(.17)$ \\
\hline
\end{tabular}

Sources: NSRB 1981-2 and 2001-2.

${ }^{a}$ Endogenous variable: instruments include household head's age and schooling level, land holdings, and price of all foods consumed interacted with individual age and sex variables, land and head's schooling and age.

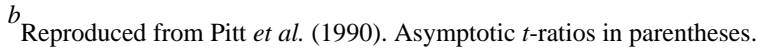




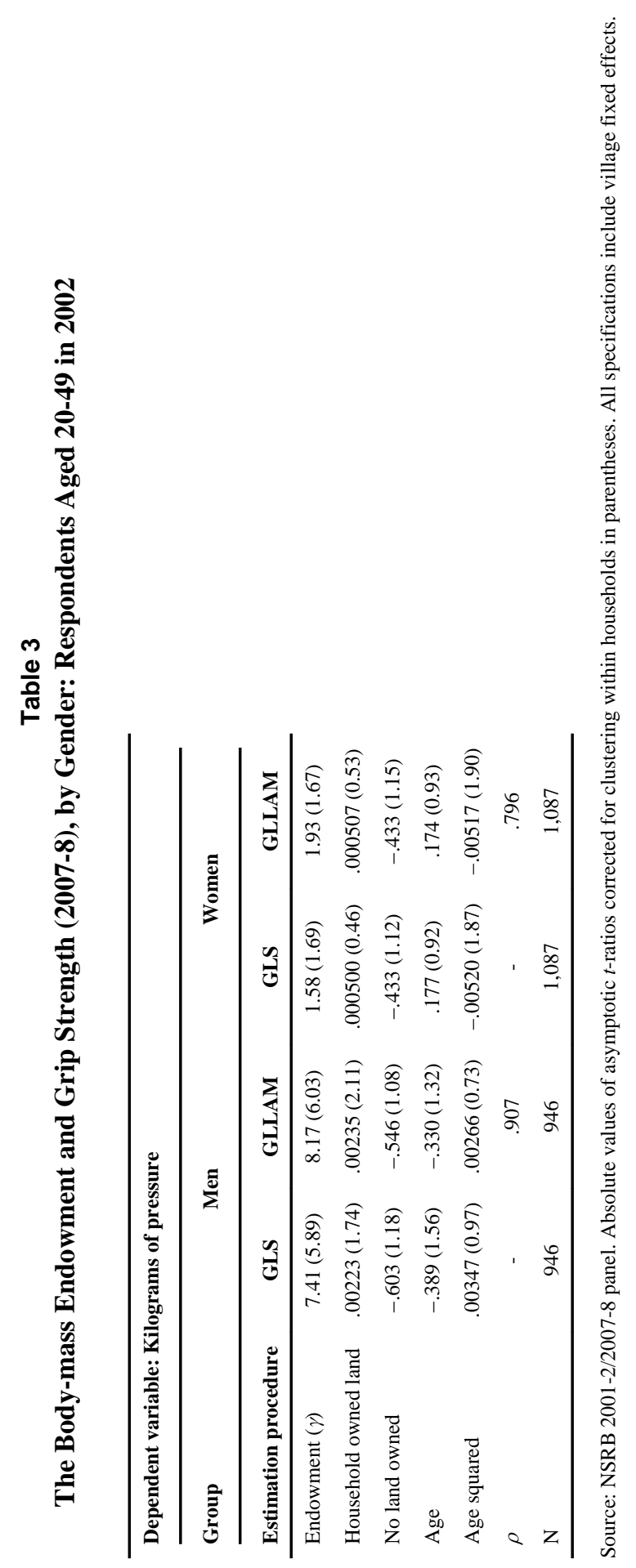

Am Econ Rev. Author manuscript; available in PMC 2014 August 21. 


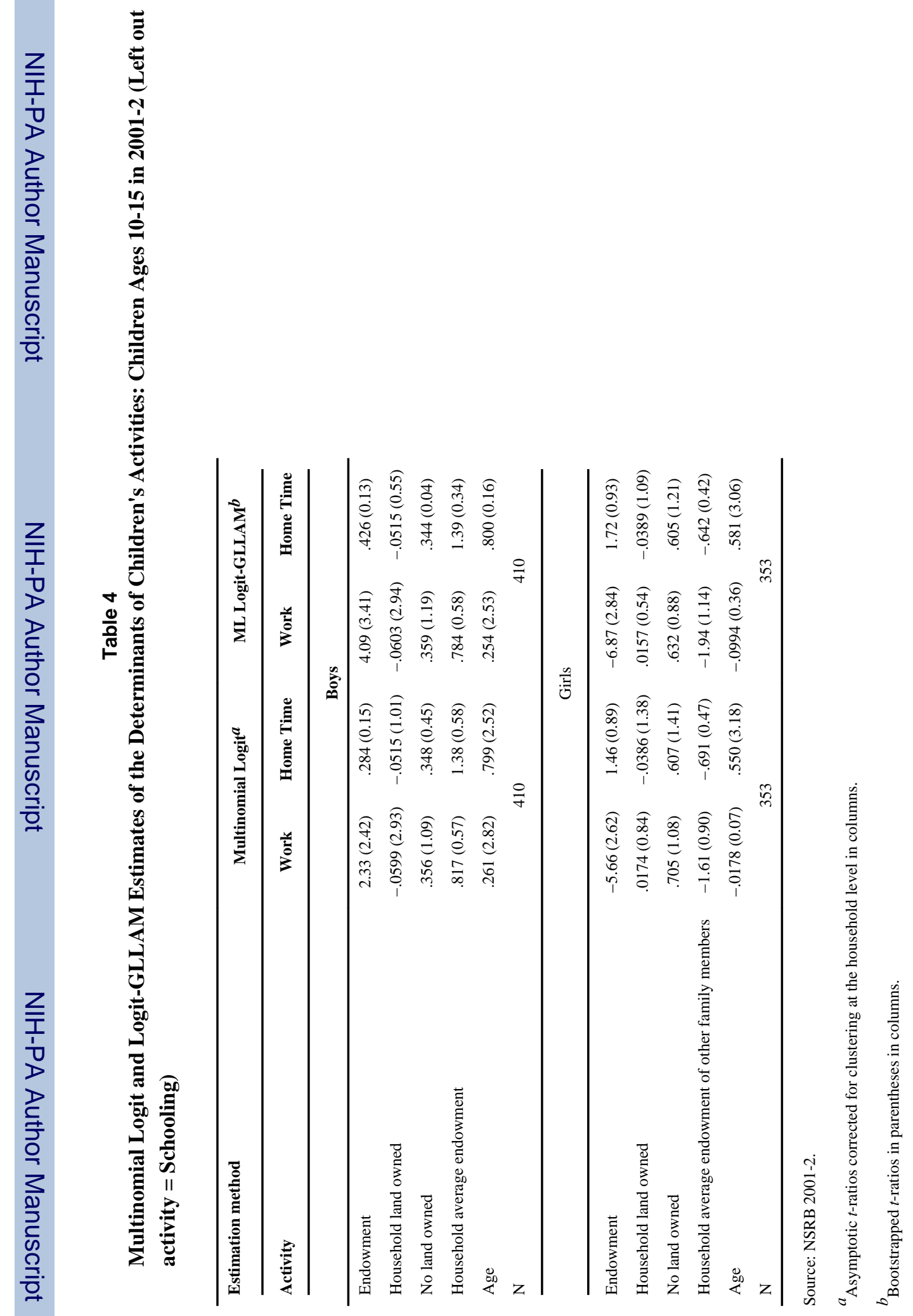




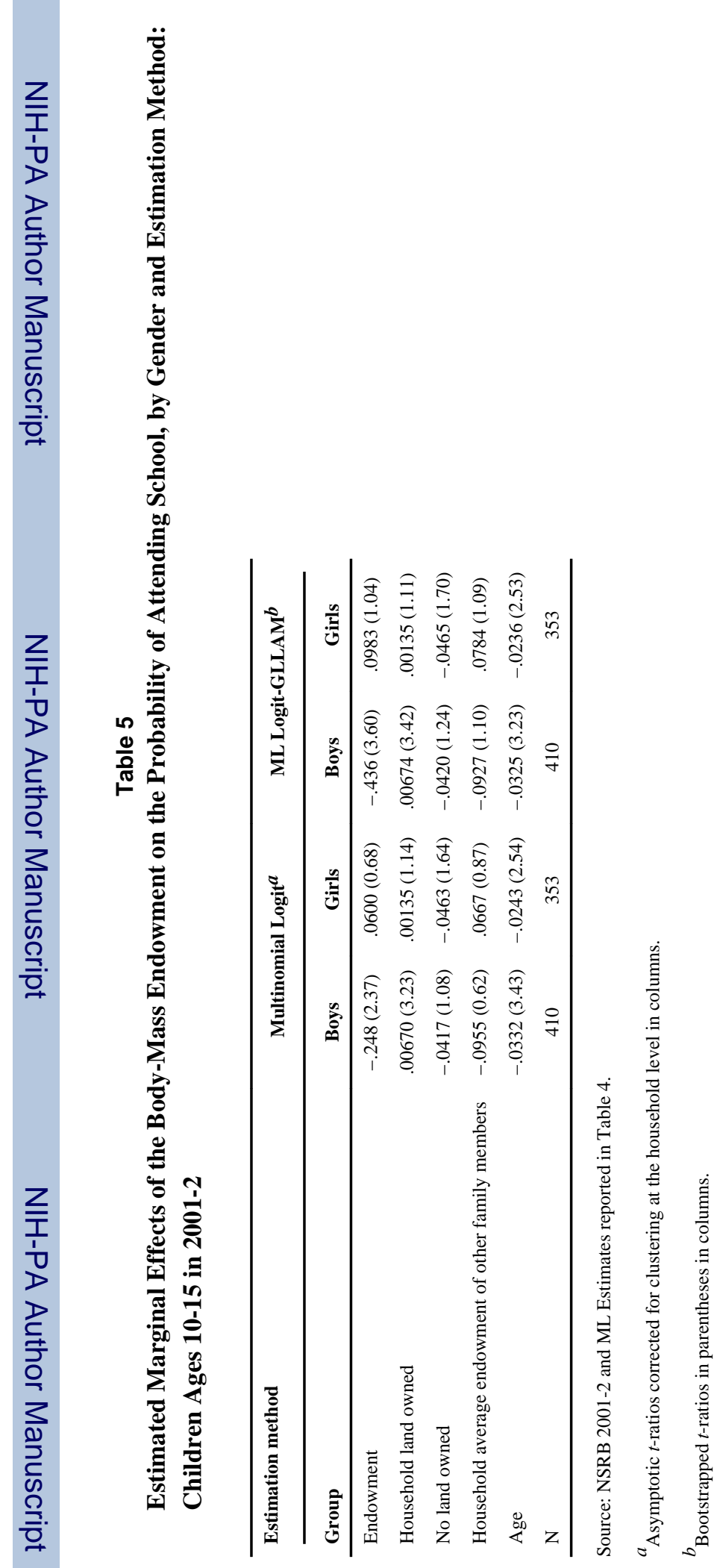

Am Econ Rev. Author manuscript; available in PMC 2014 August 21. 


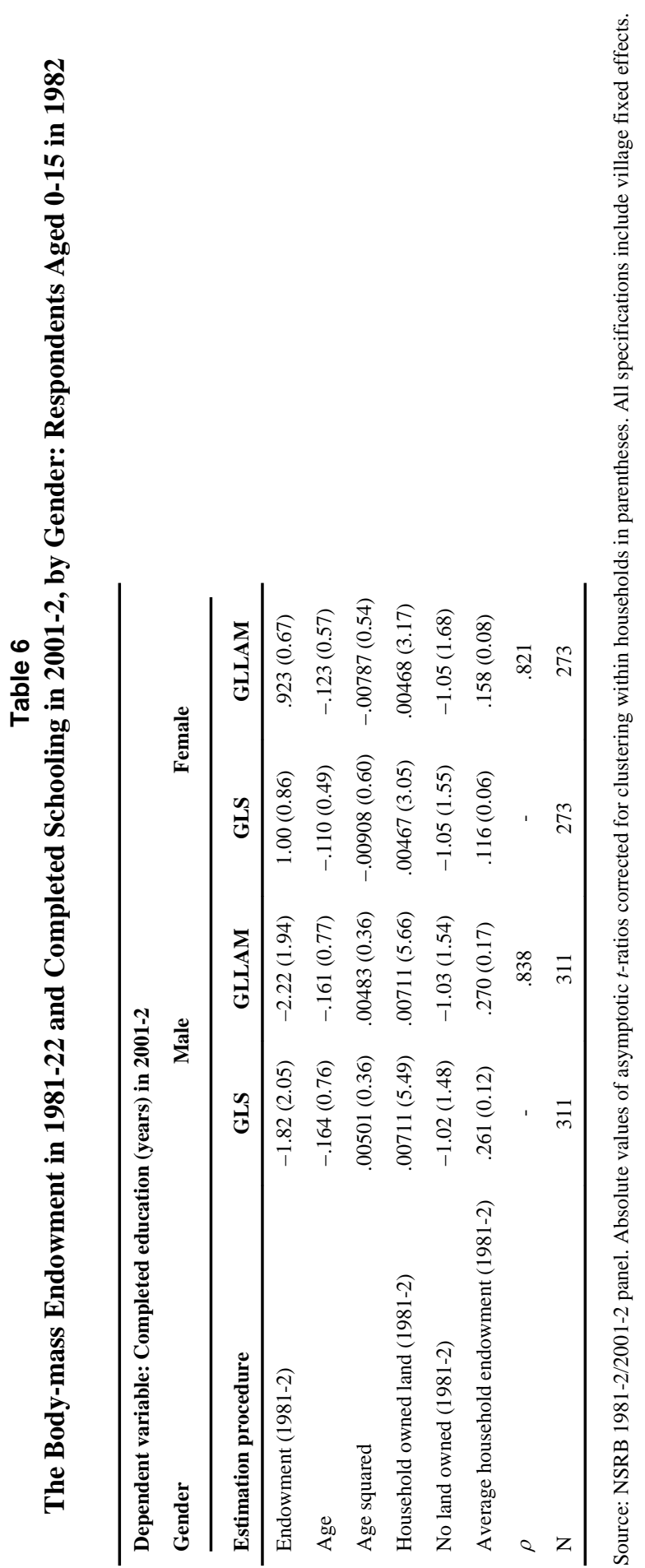

Am Econ Rev. Author manuscript; available in PMC 2014 August 21. 


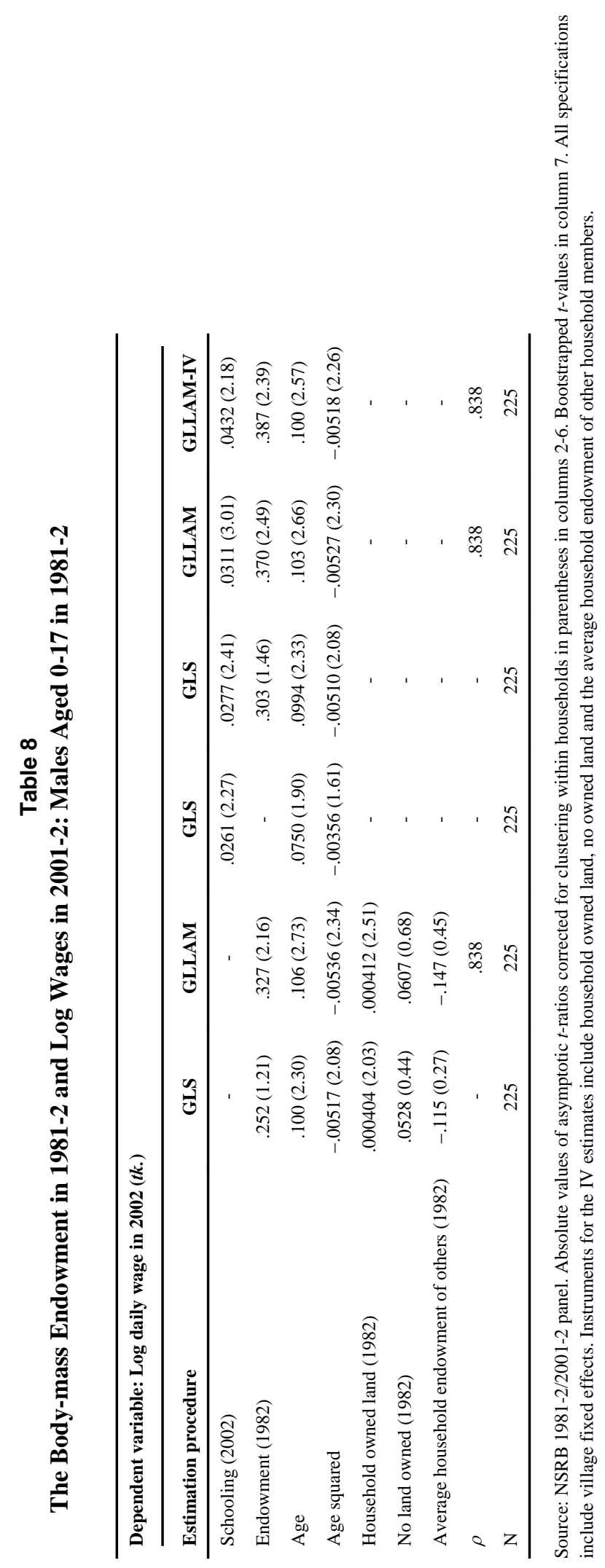

Am Econ Rev. Author manuscript; available in PMC 2014 August 21. 


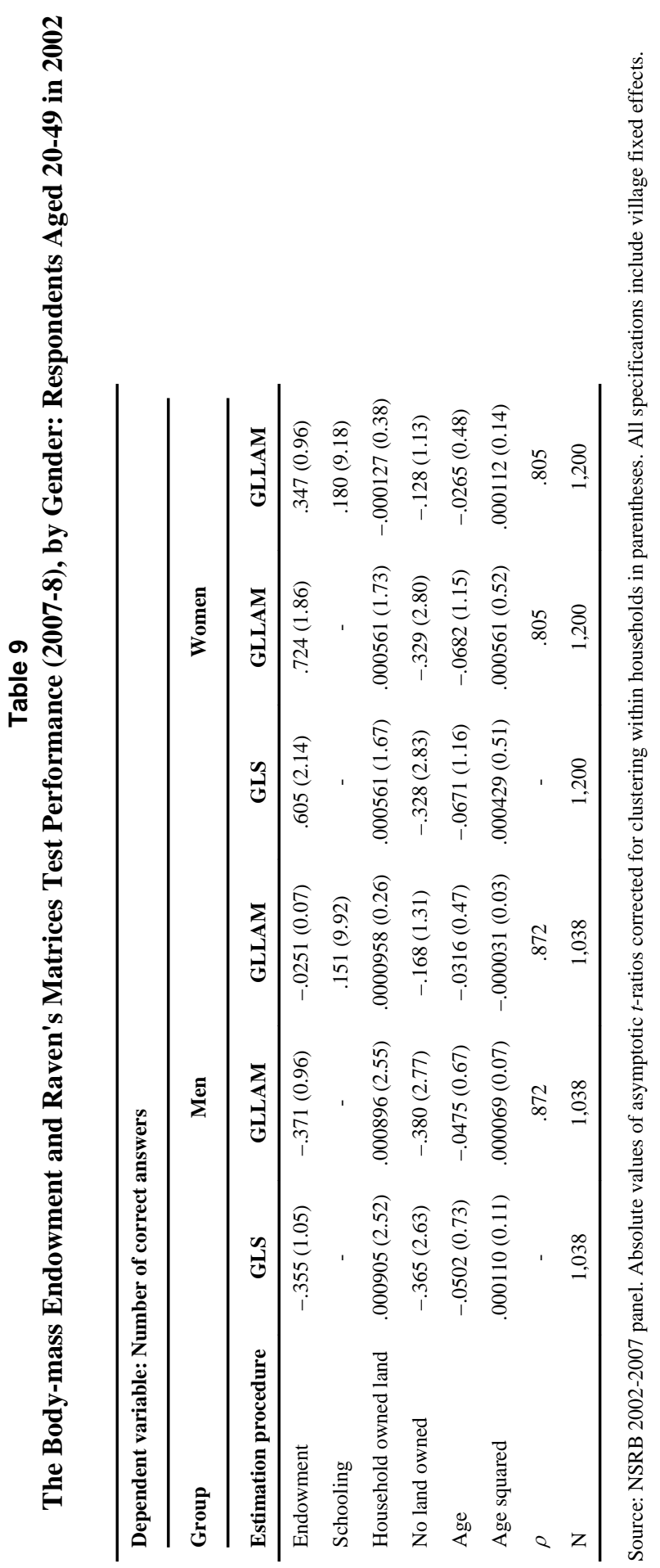




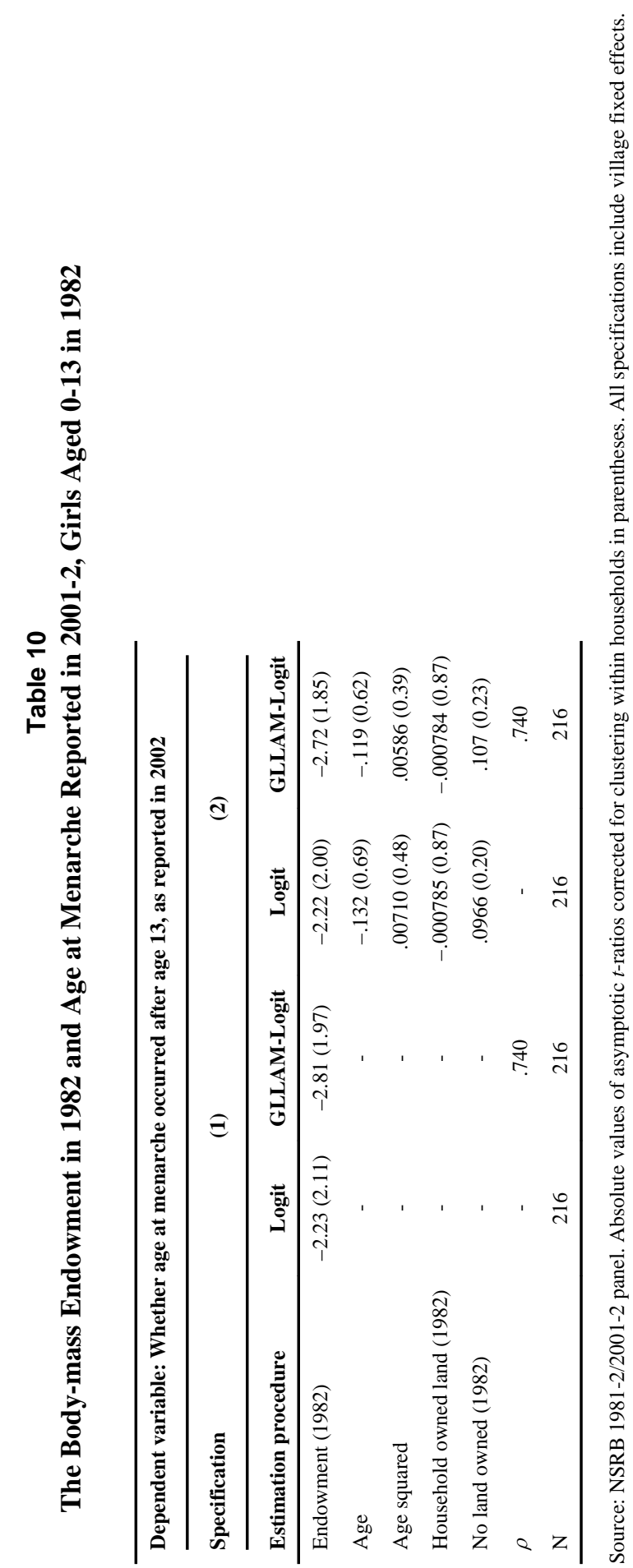

Am Econ Rev. Author manuscript; available in PMC 2014 August 21. 
